\title{
The AUSGeoid09 model of the Australian Height Datum
}

\author{
W. E. Featherstone - J. F. Kirby - C. Hirt • \\ M. S. Filmer - S. J. Claessens - N. J. Brown • \\ G. Hu - G. M. Johnston
}

Received: 7 June 2010 / Accepted: 15 October 2010 / Published online: 19 November 2010

(C) The Author(s) 2010. This article is published with open access at Springerlink.com

\begin{abstract}
AUSGeoid09 is the new Australia-wide gravimetric quasigeoid model that has been a posteriori fitted to the Australian Height Datum (AHD) so as to provide a product that is practically useful for the more direct determination of AHD heights from Global Navigation Satellite Systems (GNSS). This approach is necessary because the AHD is predominantly a third-order vertical datum that contains a $\sim 1 \mathrm{~m}$ north-south tilt and $\sim 0.5 \mathrm{~m}$ regional distortions with respect to the quasigeoid, meaning that GNSSgravimetric-quasigeoid and AHD heights are inconsistent. Because the AHD remains the official vertical datum in
\end{abstract}

W. E. Featherstone $(\bowtie)$ J. F. Kirby · C. Hirt · M. S. Filmer · S. J. Claessens

Western Australian Centre for Geodesy, and The Institute for Geoscience Research, Curtin University of Technology, GPO Box U1987, Perth, WA 6845, Australia

e-mail: W.Featherstone@curtin.edu.au

J. F. Kirby

e-mail: J.Kirby@curtin.edu.au

C. Hirt

e-mail: C.Hirt@curtin.edu.au

M. S. Filmer

e-mail: M.Filmer@curtin.edu.au

S. J. Claessens

e-mail: S.Claessens@ curtin.edu.au

\section{N. J. Brown · G. Hu · G. M. Johnston}

National Geospatial and Reference Systems Project,

Geospatial and Earth Monitoring Division, Geoscience Australia,

GPO Box 378, Canberra, ACT 2601, Australia

e-mail: Nicholas.Brown@ga.gov.au

$\mathrm{G} . \mathrm{Hu}$

e-mail: Guorong.Hu@ga.gov.au

G. M. Johnston

e-mail: Gary.Johnston@ga.gov.au
Australia, it is necessary to provide GNSS users with effective means of recovering AHD heights. The gravimetric component of the quasigeoid model was computed using a hybrid of the remove-compute-restore technique with a degree-40 deterministically modified kernel over a one-degree spherical cap, which is superior to the removecompute-restore technique alone in Australia (with or without a cap). This is because the modified kernel and cap combine to filter long-wavelength errors from the terrestrial gravity anomalies. The zero-tide EGM2008 global gravitational model to degree 2,190 was used as the reference field. Other input data are $\sim 1.4$ million land gravity anomalies from Geoscience Australia, $1^{\prime} \times 1^{\prime}$ DNSC2008GRA altimeter-derived gravity anomalies offshore, the $9^{\prime \prime} \times 9^{\prime \prime}$ GEODATA-DEM9S Australian digital elevation model, and a readjustment of Australian National Levelling Network (ANLN) constrained to the CARS2006 mean dynamic ocean topography model. To determine the numerical integration parameters for the modified kernel, the gravimetric component of AUSGeoid09 was compared with 911 GNSSobserved ellipsoidal heights at benchmarks. The standard deviation of fit to the GNSS-AHD heights is $\pm 222 \mathrm{~mm}$, which dropped to $\pm 134 \mathrm{~mm}$ for the readjusted GNSSANLN heights showing that careful consideration now needs to be given to the quality of the levelling data used to assess gravimetric quasigeoid models. The publicly released version of AUSGeoid09 also includes a geometric component that models the difference between the gravimetric quasigeoid and the zero surface of the AHD at 6,794 benchmarks. This a posteriori fitting used least-squares collocation (LSC) in cross-validation mode to determine a correlation length of $75 \mathrm{~km}$ for the analytical covariance function, whereas the noise was taken from the estimated standard deviation of the GNSS ellipsoidal heights. After this LSC surface fitting, the standard deviation of fit reduced to 
$\pm 30 \mathrm{~mm}$, one-third of which is attributable to the uncertainty in the GNSS ellipsoidal heights.

Keywords Regional quasigeoid modelling ·

Vertical datums · Heights · EGM2008 · Australia

\section{Motivation}

AUSGeoid98 (Featherstone et al. 2001) has served Australia reasonably well for over a decade, principally for the determination of Australian Height Datum (AHD; Roelse et al. 1971) heights from GNSS (Global Navigation Satellite Systems) surveys (e.g., Featherstone 2008), but also for the reduction of terrestrial geodetic-surveying data to the Geocentric Datum of Australia 1994 (GDA94) (Featherstone 1997; Featherstone and Rüeger 2000). It has also found applications in geology (Miranda et al. 2008), environmental geoscience (McLaren and Wallace 2010) and physical oceanography (Deng et al. 2009). Since 1998, several new datasets have become available, principally from the Gravity Recovery and Climate Experiment (GRACE; Tapley et al. 2004) and the EGM2008 global gravitational model (Pavlis et al. 2006), making it appropriate for the computation of a new AUSGeoid model. Another motivation is our better understanding of the many deficiencies in the AHD (e.g., Featherstone 2002, 2004, 2006; Featherstone and Filmer 2008; Filmer and Featherstone 2009), making it necessary to now model the surface of zero elevation of the AHD so as to provide a more useful 'product' for GNSS users (Featherstone 1998).

However, the high spatial resolution $(\sim 8 \mathrm{~km}$ over Australia) and good quality of EGM2008 in Australia (Claessens et al. 2009) has set new challenges for regional gravimetric geoid and quasigeoid determination because the residual component is small (shown later). Beforehand, EGM2008 has revealed previously known and some unknown problems with AUSGeoid98 (Fig. 1). The striped patterns offshore, some $>0.5 \mathrm{~m}$ in magnitude, are due to ship-track gravity data that had not been crossover adjusted (cf. Featherstone 2009), although the metadata available to the AUSGeoid98 Development Team indicated that they had been. Near Perth $\left(\sim 116^{\circ} \mathrm{E}, \sim 32^{\circ} \mathrm{S}\right)$ for instance, offsets among ship tracks of $\sim 40 \mathrm{mGal}$ also distorted AUSGeoid98 onshore. At that time, it was incorrectly attributed to the extremely steep quasigeoid gradient of $\sim 100 \mathrm{~mm} / \mathrm{km}$ associated with the mass-density contrast across the Darling Fault (Lambeck 1987; Darbeheshti and Featherstone 2009), but it was later found to be due to erroneous ship-track data (Claessens et al. 2001; Kirby 2003; Featherstone 2009). As
Fig. 1 Differences (m) between EGM2008 and AUSGeoid98 (Lambert projection)

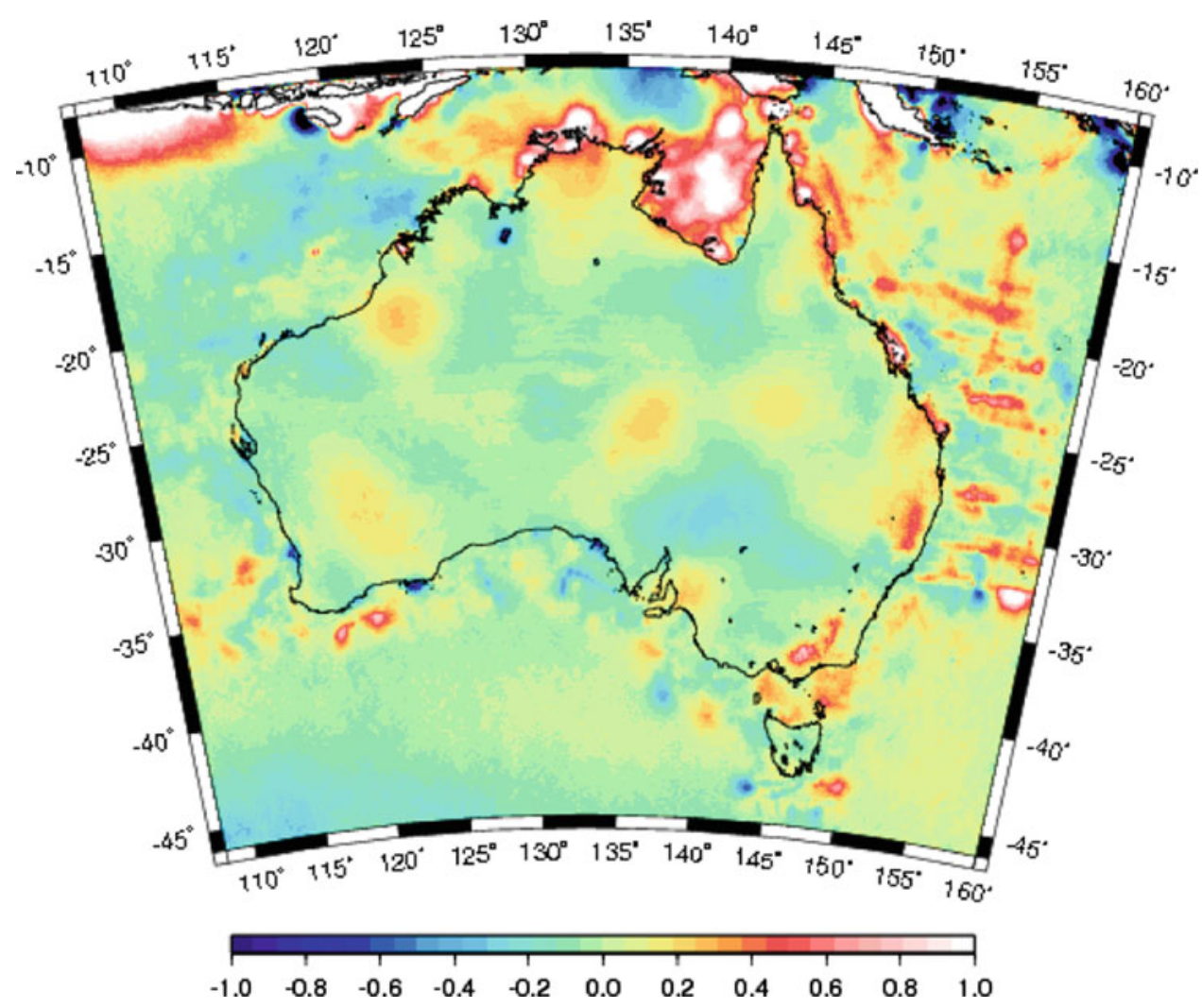


an interim solution, a small patch was applied to the released version of AUSGeoid98, where the gravimetric model was fitted to 99 GPS-AHD points using least-squares collocation (LSC) over the Perth metropolitan region (Featherstone 2000). Anecdotal evidence from Australian State and Territory geodetic agencies indicates that similar problems have been encountered in a few other coastal zones (cf. Fig. 1), but no patches were applied in these regions.

Figure 1 also shows long-wavelength differences of $\sim 0.2 \mathrm{~m}$ in magnitude on land and in marine areas where they are not swamped by the erroneous ship-track data. These are due to the use of GRACE data in EGM2008, whereas AUSGeoid98 was based on the pre-GRACE EGM96 model (Lemoine et al. 1998). Similar patterns are seen in an experimental GRACE-augmented version of AUSGeoid98 (Featherstone 2007). The $\sim 1 \mathrm{~m}$ differences in and around the Gulf of Carpentaria (centred at $\sim 140^{\circ} \mathrm{E}, \sim 15^{\circ} \mathrm{S}$ in Fig. 1) are more enigmatic. Tregoning et al. (2008) use GRACE data to identify a non-tidal variation in sea surface height in this region, which will contaminate satellite-altimeter-derived gravity anomalies and a quasigeoid model based on them (cf. Fig. 1). At present, it is not possible to isolate or quantify this effect because of the lack of decent control data in this region, so it is left for later study. In this regard, we recommend that producers of GRACE gravity field models and satellitealtimeter-derived gravity anomalies also invest some effort in the Gulf of Carpentaria region to resolve this enigma.

As an aside on terminology, AUSGeoid98 was a geoid model, but Australia is more suited to the use of a quasigeoid model because the AHD uses a normal-orthometric height system (e.g., Featherstone and Kuhn 2006). Since the normal-orthometric height system used in the AHD (Roelse et al. 1971) does not use any gravity observations, it is theoretically and practically inconsistent with a quasigeoid model, with the largest differences between normal and normal-orthometric heights reaching $\sim 0.2 \mathrm{~m}$ in the Australian Alps (Filmer et al. 2010). Although the $\sim 1 \mathrm{~m}$ northsouth tilt (Featherstone 2004, 2006) and $\sim 0.5 \mathrm{~m}$ regional distortions (Featherstone and Filmer 2008; Filmer and Featherstone 2009) in the AHD with respect to the quasigeoid are the main drivers for the need to fit the gravimetric quasigeoid to the AHD, this is an additional consideration when attempting to make AUSGeoid09 more compatible with the AHD. Finally, neither the AHD nor the quasigeoid is an equipotential surface of the Earth's gravity field, so cannot be used to describe fluid flow exactly.

Yet another motivation for AUSGeoid09 is the increased use of GNSS for absolute rather than relative height determination (cf. Featherstone 2001), where the quasigeoid height (aka height anomaly) is subtracted from the GNSS-derived ellipsoidal height to yield an AHD height at a single point. Previously, quasi/geoid height differences were applied over GNSS baselines (i.e., to ellipsoidal height differences) to determine AHD height differences (Kearsley 1988a,b), i.e., relatively so that correlated errors would cancel. This meant that, for a while, deficiencies in AUSGeoid98 went largely unnoticed. Nowadays, GNSS approaches, such as precise point positioning (PPP; Zumberge et al. 1997) or online post-processing services, such as AUSPOS (http://www.ga. gov.au/geodesy/sgc/wwwgps/), mean that only one GNSS receiver need be used; hence, a trend towards height transformations in the absolute sense (e.g., Featherstone and Dent 2002). This means that correlated errors no longer cancel as much, and AUSGeoid98 users have encountered discrepancies of $>1 \mathrm{~m}$ in some extreme cases between GNSSderived and published AHD heights. This has made it necessary to apply post-survey adjustments to the GNSS-derived AHD heights (e.g., Featherstone et al. 1998a), which is particularly inconvenient for real-time GNSS applications (e.g., Featherstone and Stewart 2001).

As an interim solution (i.e., until the AHD can be redefined or some other reference surface adopted for all heights in Australia), it is meanwhile pragmatic to distort the gravimetric-only quasigeoid to better model the surface of zero elevation of the AHD (cf. Featherstone 1998), and we have already conducted experiments in this regard (Featherstone 2000; Soltanpour et al. 2006; Featherstone and Sproule 2006; Darbeheshti and Featherstone 2010). In much of the geodetic literature, this has been called a 'correction' or 'corrector' surface, ${ }^{1}$ but which is a misnomer because the gravimetric quasi/geoid is not being corrected at all; it is being distorted to fit a vertical datum that also contains errors. Although this approach does give a practically useful product for the more direct transformation of GNSS heights to the AHD, it does not necessarily provide an improved model of the classical quasigeoid. Moreover, it does not mean that the problems with the AHD have been resolved; they have just been masked for the time being. This important subtlety seems to have been ignored in the majority of literature on this a posteriori fitting approach.

This paper describes the computation of AUSGeoid09 as a model of the surface of zero elevation of the AHD, focussing partly on the new challenges (and benefits) that EGM2008 has set for regional quasigeoid modelling. As input data, AUSGeoid09 uses EGM2008 to degree 2,190 as the reference field, DNSC2008GRA altimeter-derived gravity anomalies offshore (Andersen et al. 2010) because the Australian ship-track data are unreliable (Featherstone 2009), recomputed land gravity anomalies (Hackney and Featherstone 2003) from Geoscience Australia's national gravity database (Murray 1997), a $9^{\prime \prime} \times 9^{\prime \prime}$ grid of gravimetric terrain corrections (cf. Kirby and Featherstone 2002), spiritlevelled heights from the Australian National Levelling

\footnotetext{
1 An exception is the US National Geodetic Survey, which uses the term 'conversion' surface (cf. Smith and Roman 2001).
} 
Fig. 2 Coverage of the July 2009 release of Geoscience Australia's land gravity database

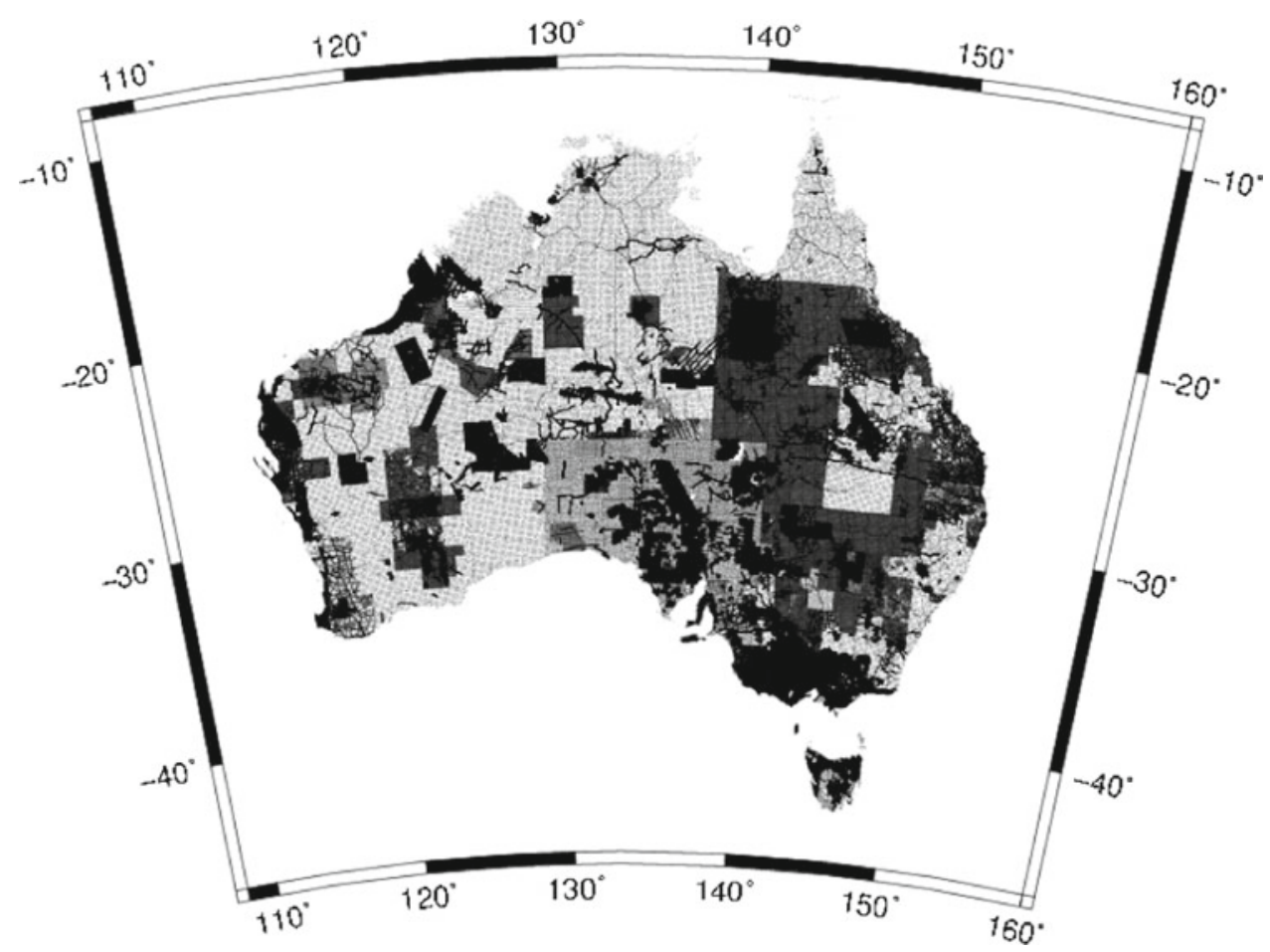

Network (ANLN), mean dynamic ocean topography estimates at 32 tide-gauges from the CARS2006 climatological model (Ridgway et al. 2002), and around 1,000 GNSSobserved ellipsoidal heights at benchmarks. One key difference in the Australian case is that EGM2008 uses the $5^{\prime} \times 5^{\prime}$ DTM2006 elevation model (Pavlis et al. 2006), whereas AUSGeoid09 uses the $9^{\prime \prime} \times 9^{\prime \prime}$ GEODATA-DEM9S elevation model (Hutchinson et al. 2008). AUSGeoid09 is provided at a $1^{\prime} \times 1^{\prime}$ grid resolution over the area $108^{\circ} \mathrm{E} \leq$ $\lambda \leq 160^{\circ} \mathrm{E}, 8^{\circ} \mathrm{S} \leq \varphi \leq 46^{\circ} \mathrm{S}$, which reduces interpolation errors for users, but has to be balanced against the file-size of $\sim 236 \mathrm{Mb}$ ( $>7$ million points).

\section{Data pre-processing}

\subsection{EGM2008}

The fully normalised zero-tide spherical harmonic coefficients of EGM2008, to degree 2,190, were used as the reference field for AUSGeoid09. The synthesis used a slightly modified version of the harmonic_synth. f software (http://earth-info.nga.mil/GandG/wgs84/gravitymod/ egm2008/index.html), adapted to run on our Sun UNIX workstations and to make the outputs compatible with our data formats. All values were computed relative to GRS80 (Moritz 1980) so as to be compatible with the GDA94, and including a correct computation of the zerodegree term rather than via the erroneous treatment in Kirby and Featherstone (1997). Point quasigeoid heights were computed on a $1^{\prime} \times 1^{\prime}$ grid over the area $108^{\circ} \mathrm{E} \leq$ $\lambda \leq 160^{\circ} \mathrm{E}, 8^{\circ} \mathrm{S} \leq \varphi \leq 46^{\circ} \mathrm{S}$, whereas the ellipsoidal approximation option in harmonic_synth.f was used to approximate areal means by point gravity anomalies for each $1^{\prime} \times 1^{\prime}$ grid cell.

\subsection{GA land gravity data}

The gravimetric component of AUSGeoid09 uses the July 2009 land gravity data release from Geoscience Australia (GA), which was downloaded via GADDS (http://www. gadds.ga.gov.au/). The GA gravity database then comprised $\sim 1.4$ million observations (Fig. 2), roughly twice as many as used in AUSGeoid98. When compared with Fig. 1 in Featherstone et al. (2001), the dense patches in Fig. 2 here reflect the newer data collected in areas of commercial resource prospectivity or scientific interest.

Most of these newer gravity data were coordinated using GNSS in dense grids (typically $2-4 \mathrm{~km}$, but down to $50 \mathrm{~m}$ in some areas of particular interest or of steep gravity gradients), but the 7-11-km-spaced reconnaissance gravity data (Fraser et al. 1976) is still held in the GA database (paler areas in Fig. 2). Unfortunately, however, there is no documentation on the GNSS reference frame used [e.g., GDA94 versus the various realisations of the International Terrestrial Reference Frame (ITRF)] or the quasi/geoid model used to recover the elevations of these newer gravity observations. This is a deficiency in the GA database because the provenance of the data cannot be scrutinised. Moreover, any errors 
in the quasi/geoid model used to transform heights will propagate into the computed gravity anomalies.

Anecdotal evidence from some of the gravity data acquisition contractors suggests that a variety of quasi/geoid models have been used over time. However, these are likely to be more accurate than the heights in the reconnaissance data ( $\sim \pm 10 \mathrm{~m}$; Barlow 1977), which were determined with barometers, but could be long-wavelength in nature because of the clover-leaf pattern used to control barometer and gravimeter drift (Bellamy and Lodwick 1968). It is conceivable that, over time, Australia will be completely covered by GNSS-coordinated gravity surveys, thus allowing the solution of the quasigeoid via a fixed boundary-value problem (cf. Kirby 2003). The short-wavelength quality of the Australian gravity anomalies appears to be generally quite good, despite the vast areas involved and challenging conditions for fieldwork. Sproule et al. (2006) used LSC to reject only $\sim 100$ land gravity observations in the GA database. Unfortunately, neither the raw data nor the metadata are in a format that allows for automated error propagation of mean gravity anomaly error estimates. This is another deficiency in the GA gravity database.

In addition, GA has adopted a new gravity datum called the Australian Absolute Gravity Datum 2007 (AAGD07; Tracey et al. 2007), but which is not connected to the International Gravity Standardisation Network (IGSN71; Morelli et al. 1971). Instead, it is based on Micro-g Lacoste A10 absolute gravity observations at 60 sites across Australia. The datum change was applied by GA by subtracting $78 \mu \mathrm{Gal}$ from all gravity values in the database, which had previously been tied to the IGSN71 (Wellman et al. 1985). Since a constant gravity anomaly integrated over a spherical cap yields a constant quasigeoid height (cf. Featherstone and Olliver 1997), the constant bias, estimated to be $<10 \mathrm{~mm}$, from this different gravity datum is insignificant in relation to the facts that the zero-degree term in the quasigeoid is indeterminate and vertical datums are offset from one another. Finally, the tidal system of the GA gravity observations remains unknown (cf. Featherstone et al. 2001).

\subsection{Computation of mean land gravity anomalies}

Determination of the quasigeoid by discretized numerical integration requires mean gravity anomalies on the topography, as per Molodensky's theory (Molodensky et al. 1962; Heiskanen and Moritz 1967). Because land gravity observations are often sampled irregularly based on the ease of field access, care needs to be exercised to determine representative mean gravity anomalies. Different approaches have been used in different parts of the world (e.g., Janak and Vaníček 2005), but the Australian situation is somewhat unique. As an ancient continent, Australia is heavily weathered with a mean topographic height of $\sim 270 \mathrm{~m}$ (Hirt et al. 2010), but it exhibits some very large $\left(>500 \mathrm{kgm}^{-3}\right)$ mass-density contrasts due to geology, ranging from soft sediments to dense Archean cratons. For instance, gravity anomalies change by over $100 \mathrm{mGal}$ over a few kilometres across the Darling Fault in Western Australia (Darbeheshti and Featherstone 2009).

Goos et al. (2003) and Zhang and Featherstone (2004) have shown that simple planar Bouguer gravity anomalies in Australia are well suited to interpolation, which is fortuitous because this allows the computation of more representative mean gravity anomalies on the topography by reconstruction using a high-resolution digital elevation model (Featherstone and Kirby 2000). First, point simple planar Bouguer gravity anomalies were recomputed from the GA database using geodetic formulas (Hackney and Featherstone 2003) for all $\sim 1.4$ million land gravity observations. A constant topographic mass-density of $2,670 \mathrm{kgm}^{-3}$ was used as there is yet no 3D topographic mass-density model of Australia, and Molodensky's theory for the computation of the quasigeoid makes no assumption about topographic massdensity.

These point simple planar Bouguer gravity anomalies were interpolated onto the same $9^{\prime \prime} \times 9^{\prime \prime}$ grid as the GEODATA-DEM9S elevation model using the GMT (Wessel and Smith 1998) "surface" algorithm, which uses a tensioned spline (Smith and Wessel 1990). Based on the recommendation in the GMT manual pages for potential field data, a tension factor of $T=0.25$ was used. In this regard, there remains some conjecture as to whether a $2 \mathrm{D}$ interpolation technique should be applied to what is effectively a 3D field (e.g., Forsberg and Tscherning 1981; Vaníček et al. 2004). This remains for future study, but based on the comparisons between interpolated and observed Bouguer anomalies (cf. Sproule et al. 2006; Goos et al. 2003; Zhang and Featherstone 2004), this 2D interpolation approach appears sufficient in Australia. Spherical Bouguer anomalies and their associated terrain corrections were not used because they are similar to the planar Bouguer anomalies (Kuhn et al. 2009) so offer no apparent advantage during this gridding stage.

Molodensky free-air anomalies (i.e., on the topography) were 'reconstructed' from the $9^{\prime \prime} \times 9^{\prime \prime}$ grid of interpolated Bouguer anomalies by adding the simple planar Bouguer plate term computed from the GEODATA-DEM9S elevation model. The $9^{\prime \prime} \times 9^{\prime \prime}$ grid of planar gravimetric terrain corrections, used to approximate the Molodensky G1 term (cf. Moritz 1968; Sideris 1990; Val'ko et al. 2008), were then added to the $9^{\prime \prime} \times 9^{\prime \prime}$ grid of reconstructed Molodensky free-air anomalies. This high-resolution grid was generalised using area-weighted means to give a $1^{\prime} \times 1^{\prime}$ grid of mean Molodensky gravity anomalies on the topography. The full justification for this approach is detailed in Featherstone and Kirby (2000). 


\subsection{DNSC2008GRA marine gravity anomalies}

Given that ship-track gravity data around Australia are generally unreliable, and most cannot be crossover adjusted because of ill-conditioning (Featherstone 2009), altimeterderived gravity anomalies had to be used exclusively in AUSGeoid09. DNSC2008GRA (Andersen et al. 2010) was chosen over Sandwell and Smith v18.1 (Sandwell and Smith 2009) based on a comparison of the two with a limited amount of test data in the Australian coastal zone (Claessens 2010). This showed that EGM2008GRA agrees more closely with subsets of reliable shipborne and airborne gravity data than Sandwell and Smith v18.1 in two test areas close $(<50 \mathrm{~km})$ to the Australian coast. In addition, the EGM2008 Development Team took DNSC2008GRA to be "better" within $\sim 195 \mathrm{~km}$ of the coasts (Pavlis et al. 2006). As such, DNSC2008GRA was chosen in preference because AUSGeoid09 will have a greater usage near the coasts of Australia, where the majority of the population resides.

\subsection{Merging land and marine data: the coastal zone problem}

Modelling the geoid in the coastal zone is notoriously problematic (e.g., Hipkin 2000), but merging the land and marine gravity data highlighted a problem that had not been noticed previously by the AUSGeoid98 Development Team. The high-resolution GMT shoreline with island options (Wessel and Smith 1996) was first used to mask marine regions from the $1^{\prime} \times 1^{\prime}$ land gravity anomaly grid (Sect. 2.3) and to mask land regions from the $1^{\prime} \times 1^{\prime}$ DNSC2008GRA marine gravity anomaly grid (Sect. 2.4), with both then merged using the GMT "grdmath" command. However, this showed some spurious features in the coastal zones, the largest of which was at Fraser Island (centred at $\sim 153^{\circ} \mathrm{E}, \sim 25^{\circ} \mathrm{S}$ ).

Figure 3 (panel a) shows that no gravity observations are available on Fraser Island, so gridding Bouguer anomalies results in undesirable extrapolation over this island (Fig. 3, panel b) such that the reconstruction technique (Sect. 2.3) gives values that are incorrect by $>20 \mathrm{mGal}$ (Fig. 3, panel c). This is also an example where EGM2008 has been beneficial to regional quasigeoid modelling, as it helped to confirm that this was a problem area. Since EGM2008 is such a good fit to the Australian gravity field (cf. Claessens et al. 2009), with $95 \%$ of residual gravity anomalies being $<5 \mathrm{mGal}$ (Table 1 ), such a spurious feature can be identified easily.

In order to avoid contamination of the reconstructed mean anomalies in the coastal zone by extrapolation of the land Bouguer anomalies, the latter were augmented by DNSC2008GRA marine gravity anomalies, where the DNSC2008GRA anomalies were concatenated with the land Bouguer gravity anomalies before the GMT "surface" gridding process. GMT was used to mask the EGM2008-
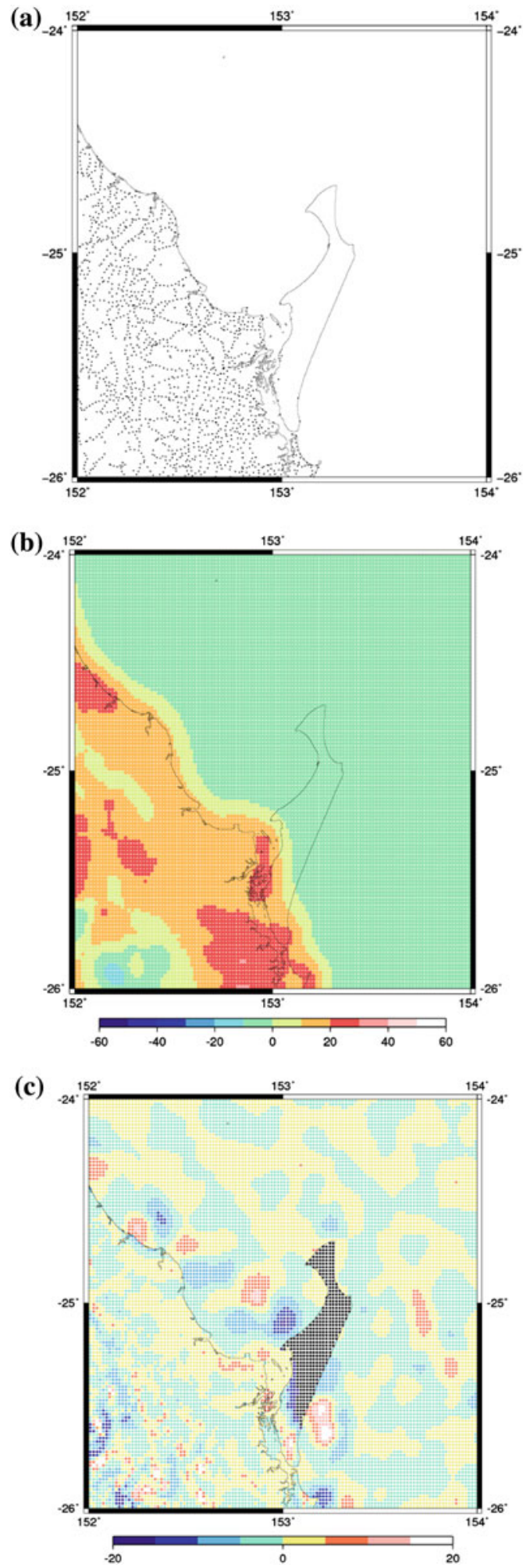

Fig. 3 a Coverage of land gravity observations showing that no gravity observations are available on Fraser Island; b if these point gravity anomalies are gridded, the Bouguer gravity anomalies are extrapolated ocean-wards; c when these Bouguer anomalies are reconstructed to give Molodensky free-air anomalies, >20 mGal errors result, which are incompatible with the DNSC2008GRA gravity anomalies offshore (Mercator projection) 
Table 1 Statistics of the residual mean gravity anomalies used in the gravimetric components of AUSGeoid98 and AUSGeoid09, showing the improvement offered by EGM2008

\begin{tabular}{lll}
\hline Units (mGal) & $\begin{array}{l}\text { Residual mean gravity anomalies } \\
\text { used for AUSGeoid98 after removal } \\
\text { of EGM96 to degree 360 }\left(2^{\prime} \times 2^{\prime}\right. \\
\text { grid) }\end{array}$ & $\begin{array}{l}\text { Residual mean gravity anomalies } \\
\text { used for AUSGeoid09 after removal } \\
\text { of EGM2008 to degree 2,190 } \\
\left(1^{\prime} \times 1^{\prime} \text { grid }\right)\end{array}$ \\
\hline No & $1,781,101$ & $7,113,600$ \\
Max & 197.44 & 105.97 \\
Min & -282.70 & -87.69 \\
Mean & -0.90 & -0.09 \\
STD & \pm 15.01 & \pm 2.49
\end{tabular}

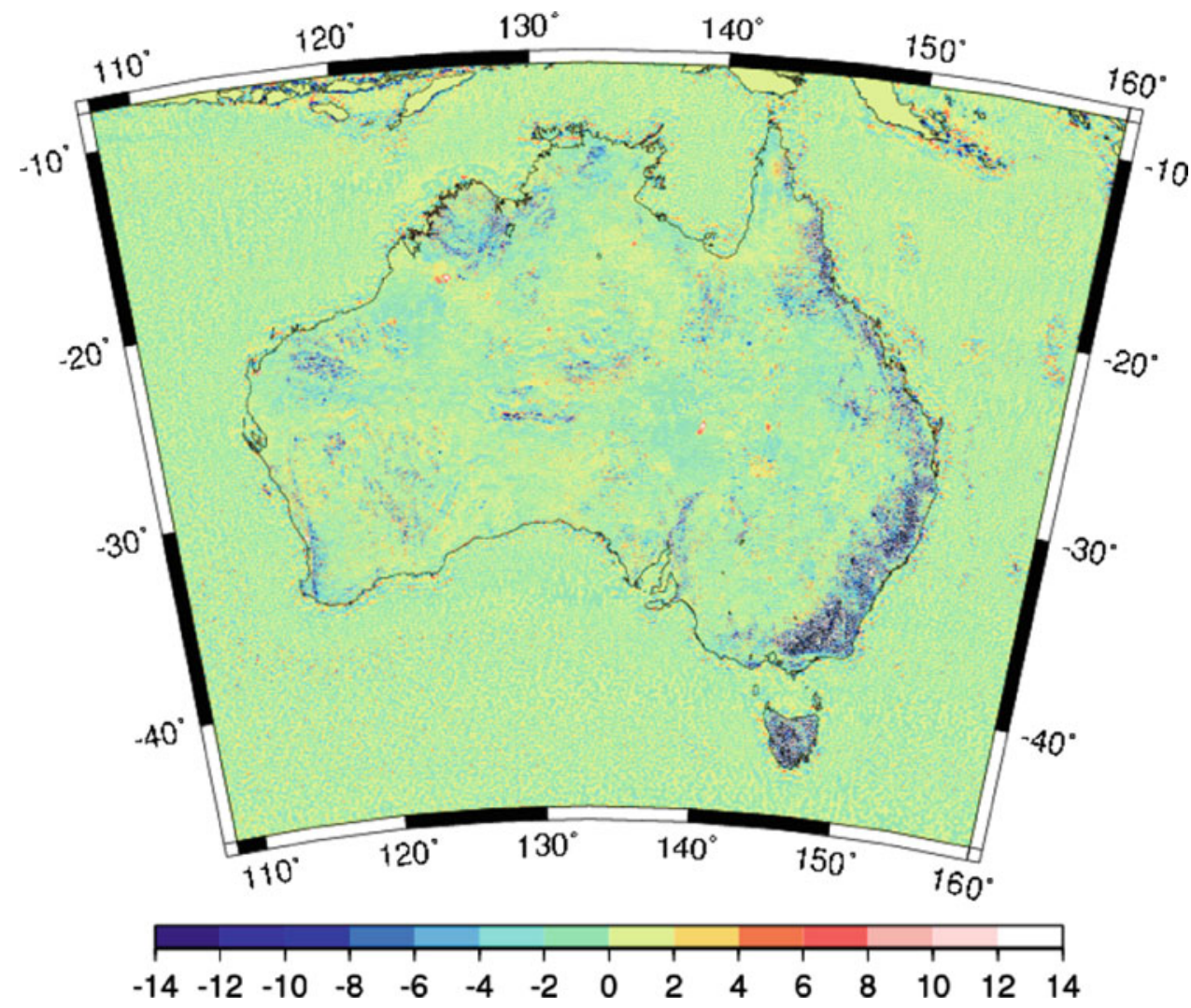

Fig. 4 Residual mean gravity anomalies (mGal) used to compute AUSGeoid09 generated gravity anomalies on land from DNSC2008GRA. While this concatenation alleviated the problem of extrapolation, numerous other problems of modelling the quasi/geoid in the coastal zone remain (cf. Hipkin 2000; Andersen and Knudsen 2000), are not explored further here, and remain for future study. However, the lack of gravity data on Fraser Island means that AUSGeoid09 will be less precise in this region.

\subsection{Residual mean gravity anomalies}

The $1^{\prime} \times 1^{\prime}$ grid of EGM2008 gravity anomalies (Sect. 2.1) were subtracted from the merged land-ocean grid (Sect. 2.5) to yield residual mean gravity anomalies (Fig. 4; Table 1).
These residual gravity anomalies are generally small, much smaller than those used for AUSGeoid98 (Table 1), suggesting that it will be difficult to improve much upon EGM2008 (demonstrated later). The larger residual gravity anomalies ( $>10 \mathrm{mGal}$ in magnitude) occur in Australian mountainous regions (e.g., along the south-eastern seaboard and Tasmania) or where the gravity field is variable due to geology (e.g., the Darling Fault along the south-western seaboard). The extreme values occur in the oceanic trenches to the north of Australia, but the use of the limited spherical cap (described later) means that they do not contaminate the quasigeoid solution on the Australian mainland.

The high-resolution GMT shoreline with island options was used to set residual gravity anomalies to zero over all land areas to the north of Australia (Fig. 4), where no gravity 
data were available to the AUSGeoid09 Development Team. If not done, spuriously large residual anomalies contaminate the results because of extrapolation of the large gravity gradients associated with the subduction zone between the Australian and Eurasian and Pacific Plates. Because no data have been used on land in these regions, AUSGeoid09 must be used with caution in countries to the north of Australia.

\subsection{GNSS-ANLN data}

A dataset of around 1,000 GNSS-levelling points was used to test the gravimetric quasigeoid solutions so as to empirically select the kernel modification parameters (shown later). It was first edited to remove eight points located on islands that cannot be connected to the AHD by spirit levelling. A further 17 points were removed as outliers during the gravimetric quasigeoid tests (shown later), mainly in southern Queensland, where the ANLN is poor because of the larger number of one-way third-order levelling lines (shown as red in Fig. 5). This left 911 GNSS-levelling points.

Some of the larger outliers $(>1 \mathrm{~m})$ were found later to result from GNSS antenna height measurement blunders/omissions, but errors in the GNSS-ANLN connection may also contribute. The antenna height blunders were corrected before the fitting procedure (Sect. 4), but omitted from the analysis of the gravimetric quasigeoid model. The coverage of the GNSS-levelling points is also rather patchy
(Figs. 9, 10), not only because of the remote areas involved and challenging field conditions, but also because some Australian States and Territories did not supply enough raw GNSS data for reprocessing by GA before the gravimetric quasigeoid computations were performed. However, additional data have been used for modelling the geometric component of AUSGeoid09 (Sect. 4).

GNSS RINEX data supplied by the Australian States and Territories were processed by GA using the Bernese scientific software, version 5.0 (Dach et al. 2007) to give 3D geodetic coordinates in the ITRF2005 (epoch 2000.0) reference frame (Altamimi et al. 2007). In most cases, GNSS occupations of greater than $6 \mathrm{~h}$ were processed, with a few exceptions in Queensland so as to provide coverage in remote areas. Although ITRF2005 was used for testing the gravimetric component of AUSGeoid09, GDA94 ellipsoidal heights have been used in the fitting procedure (Sect. 4). The GNSS data processing conformed to IERS (International Earth Rotation and Reference Systems Service) 2003 standards (McCarthy and Petit 2004) and used precise "final" orbits from the International GNSS Service (IGS; Dow et al. 2009) and absolute antenna phase centre models (Schmid et al. 2007). The internally estimated precision (one sigma) of the GNSS-derived ellipsoidal heights varies between \pm 0.1 and $\pm 10 \mathrm{~mm}$ (mean $\pm 2.5 \mathrm{~mm}$ ), although this could be over-optimistic by an order of magnitude (cf. Rothacher 2002). As such, these were scaled up by 10 when modelling the geometric component
Fig. 5 Spirit-levelling traverses of the ANLN. Sections in yellow represent first order, light green is second order, thin purple is third order, dark green is fourth order, red is one-way third order and blue is 'two-way levelling' of unspecified order. The orders of Australian levelling are specified in ICSM (2007); also see Filmer and Featherstone (2009) (Mercator projection)

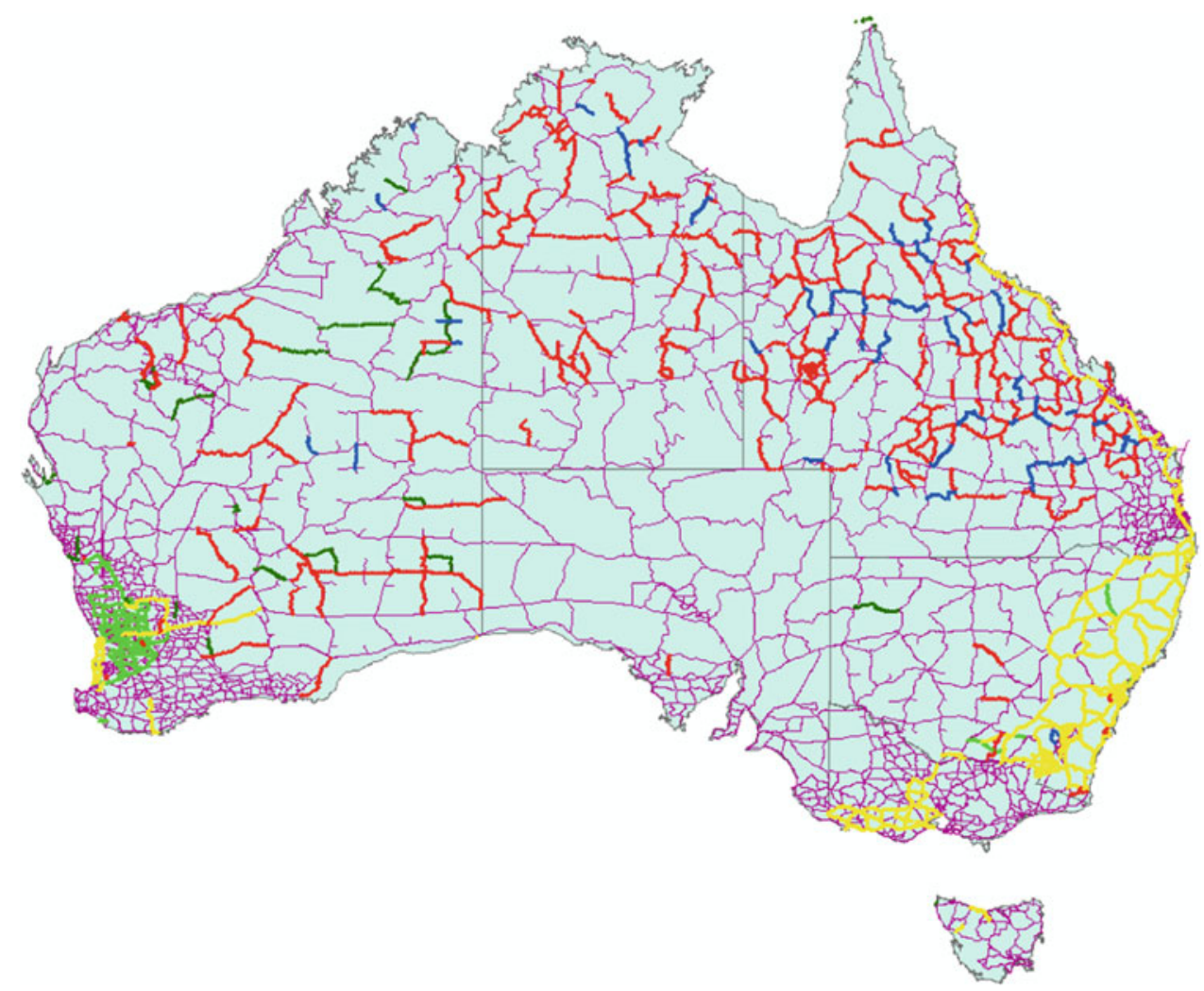


of AUSGeoid09 to fit it to the surface of zero elevation of the AHD (Sect. 4).

The precision of the GNSS ellipsoidal heights, even if scaled by an order of magnitude, is still far better than that of the spirit-levelled heights, which are the 'weak link' in the assessment of the gravimetric quasigeoid solutions in Australia, and probably elsewhere too. Since the AHD contains a $\sim 1 \mathrm{~m}$ north-south slope and $\sim 0.5 \mathrm{~m}$ regional distortions, it is not ideal for quasigeoid testing. As such, it is preferable to use a different least-squares adjustment of the ANLN that is less subject to these errors, as much as the quality of the predominantly third-order observations (Fig. 5) will permit. ANLN third-order levelling (Roelse et al. 1971) is assigned an allowable misclose of $12 \mathrm{~mm}$ per square root of the levelling loop perimeter $(\mathrm{km})$ for loop closures, which is termed class LC in ICSM (2007). Given that some loop perimeters can be $\sim 2,000 \mathrm{~km}$ (Fig. 5), errors of up to $\sim 0.5 \mathrm{~m}$ still remain largely undetectable.

Complementary studies (unpublished yet; manuscript in preparation) show that the CARS2006 climatologically driven sea surface topography (SSTop) model (Ridgway et al. 2002) accounts for most of the north-south slope in the AHD, again indicating that the original strategy of aligning the AHD with MSL (Roelse et al. 1971) is the primary cause of the north-south slope in the AHD (cf. Featherstone 2004, 2006). However, regional distortions in the AHD due to gross (e.g., observation or booking/transcription errors) and systematic (e.g., refraction, staff mis-calibration, staff/instrument settlement, etc.) levelling errors (Morgan 1992) will remain in any readjustment of the ANLN. These are found primarily in more remote regions (cf. Filmer and Featherstone 2009), where there are also fewer GNSS heights to test the gravimetric component of AUSGeoid09 (cf. Figs. 9, 10).

A preferable alternative to using the published/official AHD heights, which are contaminated by SSTop and the least-squares adjustment strategies used at the time (Roelse et al. 1971), to test the gravimetric quasigeoid models is a least-squares readjustment of the ANLN constrained at 30 mainland and two Tasmanian tide-gauges with CARS2006implied SSTop. This CARS2006-constrained readjustment option is taken to be preferable to a minimally constrained adjustment of the ANLN (fixed to just one tide-gauge; e.g., Vaníček 1991) because it appears (based on the work not yet published) that the tide-gauge constraints reduce the distortions in the adjusted heights caused by levelling errors propagating through the network. Of course, this assumes that CARS2006 is an accurate model of the separation between local mean sea level and the quasigeoid. Although not ideal, these are the only data that we have access to.

The SSTop heights were determined at the 32 AHD tidegauges using bi-cubic interpolation from the $0.5^{\circ} \times 0.5^{\circ}$ CARS2006 grid. These were added to the 1971 MSL obser- vations made at the 32 AHD tide-gauges to realise SSTopreduced height estimates. The ANLN was then least-squares adjusted, holding the ANLN-connected AHD tide-gauges fixed at their CARS2006-offset sea surface heights. The tidegauge constraints were held fixed because they are considered higher quality observations than the levelling contained in the ANLN, and CARS2006 and MSL error estimates at tide-gauges are not currently available. In addition, the normal-orthometric correction of Rapp (1961) was applied to the ANLN prior the adjustment, as for the AHD (Roelse et al. 1971), with the GNSS points connected to the ANLN using information provided by Australian State and Territory geodetic agencies.

\section{Quasigeoid computations and tests}

\subsection{Software and theoretical improvements}

In the time since the release of AUSGeoid98, the computation software and procedures at the Western Australian Centre for Geodesy have been adapted and refined. This included modification of our shell scripts to account for a newer version of GMT (Wessel and Smith 1998) and a new Sun UNIX operating system, which proved to be a time consuming and tedious activity that required many checks. All software's array dimensions were increased to handle a $1^{\prime} \times 1^{\prime}$ quasigeoid grid over the area $108^{\circ} \mathrm{E} \leq \lambda \leq 160^{\circ} \mathrm{E}, 8^{\circ} \mathrm{S} \leq \varphi \leq$ $46^{\circ} \mathrm{S}$ (AUSGeoid98 was computed on a $2^{\prime} \times 2^{\prime}$ grid over the same extents). This also involved a small increase in the swap space on the Sun UNIX workstation to handle the array dimensions.

Numerous residual gravimetric quasigeoid models were computed from the residual gravity anomalies (Fig. 4; Table 1) using the 1D-FFT numerical integration technique (Haagmans et al. 1993). The 1D-FFT software had previously been adapted to include several deterministically modified kernels over spherical caps (Featherstone and Sideris 1998; Featherstone 2003); also see Featherstone et al. (2001). Closed-loop tests have shown that this software package is capable of computing the quasigeoid to $<10 \mathrm{~mm}$, assuming error-free data.

A small correction to our fftmod.f software was needed to better compute the Featherstone et al. (1998b) deterministic kernel modification. This bug originated from an ambiguity between the starting degree in the summation used to compute the modification coefficients; this was zero in Vaníček and Kleusberg (1987) and two in Vaníček and Sjöberg (1991). Intuitively, and confirmed by the above closed-loop tests, the summation should begin at two since the degree-one terms are inadmissible in the geopotential. However, the error caused by this difference is only about 
$3 \%$, which from the values in Table 3 amounts to $<1 \mathrm{~mm}$ in the quasigeoid height.

Explicit consideration of ellipsoidal corrections to account for the spherical approximation embedded in the fundamental equation of physical geodesy (e.g., Heiskanen and Moritz 1967) was not needed. This is because they are diminished by calculating gravity anomalies from EGM2008 in ellipsoidal approximation (cf. Hipkin 2004). Rather than computing additional ellipsoidal terms (cf. Huang et al. 2003) for the deterministically modified kernel, the ellipsoidal correction can be ignored simply by using the geocentric radius to the surface of the ellipsoid of each computation point as the reference radius in Stokes's formula (Claessens 2006).

As an additional improvement over AUSGeoid98, a 9" $\times$ 9" grid of gravimetric terrain corrections (cf. Kirby and Featherstone 2002) has been used in AUSGeoid09. For AUSGeoid98, it was necessary to generalise the then available $9^{\prime \prime} \times 9^{\prime \prime}$ GEODATA-DEM9S elevation model to a $27^{\prime \prime} \times 27^{\prime \prime}$ grid (Featherstone et al. 2001). Later investigations (Kirby and Featherstone 2001) showed that this was due to errors in the earlier DEM. These have now been corrected. Remaining for future work is the computation of terrain corrections and Molodensky G1 terms from a digital elevation model derived from the Shuttle Radar Topography Mission (SRTM).

\subsection{Deterministically modified kernels and spherical caps}

By way of background, there are two seemingly 'opposing' schools of thought on the remove-compute-restore (RCR) versus the modified kernel approaches to quasigeoid determination (cf. Sjöberg 2005), but we choose to use a hybrid combination of them (cf. Featherstone et al. 2001). The benefit of the RCR approach, especially when using EGM2008, is that the residual quantities are small (Tables 1, 3; also see Figs. 4, 7) so are less subject to any approximation and numerical integration errors in the residual quasigeoid computations. The benefit of the modified kernel and a limited spherical cap is that they preferentially adapt the filtering properties of the convolution so as to reduce longwavelength errors coming from the terrestrial data (Kearsley 1988a; Gilliland 1994; Forsberg and Featherstone 1998; Vaníček and Featherstone 1998). Although seemingly unique to Australia (cf. Featherstone et al. 2001 and shown later), such a hybrid approach appears to have also been effective elsewhere (e.g., Omang and Forsberg 2002; Denker et al. 2008).

Long-wavelength and systematic errors originating from terrestrial gravity anomalies (e.g., Heck 1990) have plagued regional gravimetric quasi/geoid computations for many years, although they have more recently been masked by a posteriori fits to GNSS levelling. Because the full report or paper on EGM2008 has not yet been published, inference from Pavlis $(1998,2000)$ has been used to assume that some form of high-pass filtering of the terrestrial gravity anomalies was used during the computation of EGM2008. If no filtering is applied to the terrestrial gravity anomalies, especially over continent-sized regions, then regional quasi/geoid models will become contaminated by long-wavelength errors, which is undesirable because of the good quality of the low-degree GRACE static gravity field models. This is another challenge set by GRACE and EGM2008, where filtering of terrestrial gravity anomalies is needed for regional quasi/geoid computations. In Australia, we choose to use the modified kernel to do this, but it remains for future study to investigate other methods of filtering.

The $1^{\prime} \times 1^{\prime}$ grid of residual mean gravity anomalies (Fig. 4) was 1D-FFT numerically integrated for different kernel modification scenarios (Sect. 3.3) to produce a $1^{\prime} \times 1^{\prime}$ grid of point residual quasigeoid undulations that was added to the $1^{\prime} \times 1^{\prime}$ grid of point EGM2008 quasigeoid heights (Sect. 2.1) and then compared with both the GNSS-AHD and readjusted GNSS-ANLN data to determine suitable integration parameters. These comparisons used bicubic interpolation of absolute, rather than relative, height differences from each computed grid (cf. Featherstone 2001). The idea here is that the readjusted ANLN data are less contaminated by the north-south slope and less subject to regional distortions in the AHD, thus giving a more objective assessment of the gravimetric-only quasigeoid solution. Of course, errors in the ANLN remain a hindrance.

The residual gravimetric quasigeoid computations were performed on a 192-CPU SGI Altix 3700 Bx2 supercomputer with 366 GB of RAM that is part of the Western Australian iVEC program (http://www.ivec.org/). Even with the 1D-FFT, there are $>7$ million computation points, so this supercomputer facility has allowed us to run $>500$ combinations and permutations of various deterministic kernel modifications and their associated parameters to search for the best pair (Table 2). To demonstrate that the use of published/official AHD heights contaminates the assessment, the various solutions were also compared with the 911 GNSS-AHD data. Both datasets identified the same 17 outliers.

Figure 6 shows a representative selection of results from the $>500$ tests. Only the standard deviation (STD) of the differences is presented because the mean difference is contaminated by the inexactly known zero-degree term in the geopotential and the unknown constant offset of the AHD from a global vertical datum, although the latter has not yet been realised. The maximum and minimum values are also less informative because of the tilt and regional distortions in the AHD.

After rejection of the 17 outliers, the STD of the fit of EGM2008 to the 911 GNSS-ANLN data (the value for the zero abscissa in the left panels of Fig. 6; i.e., a zero cap means 
Table 2 Kernel modifications and parameters of cap radius and degree of modification (if applicable) used for the residual gravimetric quasigeoid computations

\begin{tabular}{lll}
\hline Kernel & Cap radii & Modification degree \\
\hline Spherical Stokes & $\begin{array}{l}0.25^{\circ}, 0.5^{\circ}, 1^{\circ}, \text { then in } 0.5^{\circ} \\
\text { increments to } 10^{\circ}, \text { and } 180^{\circ}\end{array}$ & N/A \\
\hline Wong and Gore (1969) & $\begin{array}{l}0.25^{\circ}, 0.5^{\circ}, 1^{\circ}, \text { then in } 0.5^{\circ} \\
\text { increments to } 10^{\circ}\end{array}$ & $20,40,60,80,100,120$ \\
Featherstone et al. (1998b) & $\begin{array}{l}0.25^{\circ}, 0.5^{\circ}, 1^{\circ}, \text { then in } 0.5^{\circ} \\
\text { increments to } 10^{\circ}\end{array}$ & $20,40,60,80,100,120$ \\
& &
\end{tabular}
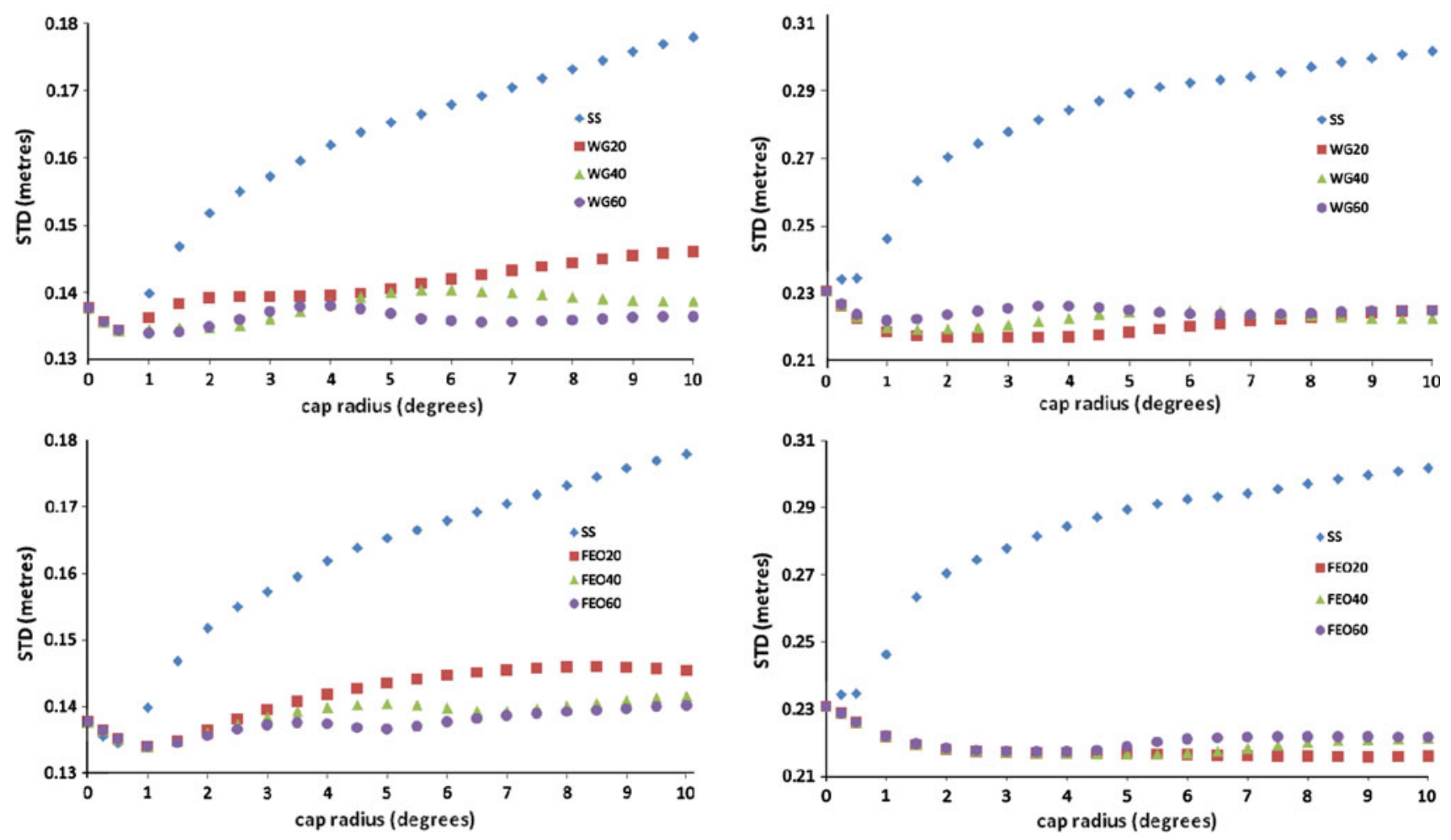

Fig. 6 Standard deviation (m) of the fit of gravimetric quasigeoid solutions to GNSS-ANLN data (left) and GNSS-AHD data (right) versus integration cap radius (degrees) for the [unmodified] spherical Stokes (SS) kernel (all panels), Wong and Gore (1969) (WG) kernel (top) and

that no Stokesian integration is performed) is $\pm 138 \mathrm{~mm}$, whereas it is $\pm 231 \mathrm{~mm}$ for the GNSS-AHD data (zero abscissa in the right panels of Fig. 6). Assuming EGM2008 is error free for the moment, Fig. 6 shows that the use of tilted and distorted AHD data degrades the assessment of the gravimetric quasigeoid models. Thus, it is recommended that much more consideration is given to the quality of the levelling data when assessing gravimetric quasi/geoid models. In addition, the identification of the 17 outliers, most of which were subsequently found to be due to omitted antenna heights, shows that EGM2008 can be used to detect such blunders.

The first consistent observation from Fig. 6 is that the spherical Stokes (SS) kernel is inappropriate, making the regional quasigeoid solution worse than EGM2008 alone

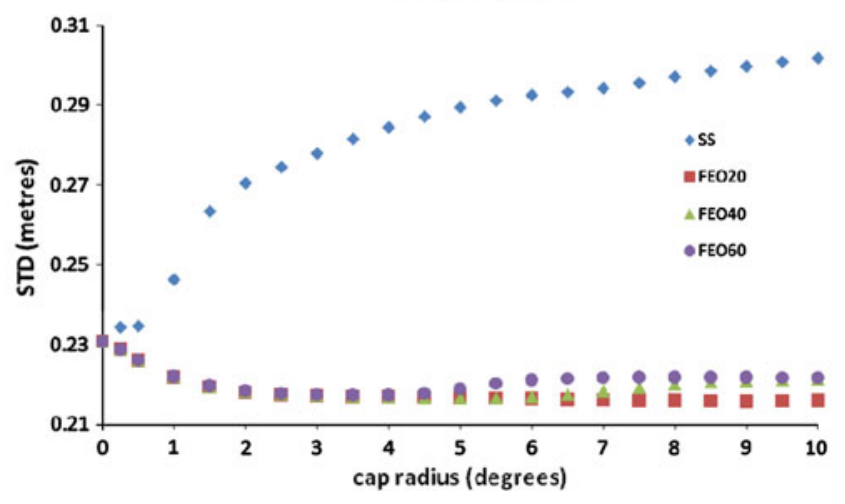

Featherstone (1998) (FEO) kernel (bottom). The numbers in the legend refer to the degree of modification used; no degree is used for the SS kernels. The different ranges for the ordinates between left and right panels shows that the contaminated AHD data adversely affect the assessments

for integration cap radii greater than $\sim 0.5^{\circ}$. This is because it permits low-frequency terrestrial gravity errors to enter the solution for larger cap radii, whereas the smaller cap radii cause it to be a more effective high-pass filter (Vaníček and Featherstone 1998). If the SS kernel is applied over the whole data area (as is often applied in the FFT-based RCR approach), the STD of fit to the GNSS-AHD data is $\pm 294 \mathrm{~mm}$, which is also worse than EGM2008 alone ( $\pm 231 \mathrm{~mm})$. As such, the good quality of EGM2008 means that more attention has to be paid to filter the terrestrial gravity anomalies and that the SS kernel is only appropriate when applied over small cap radii, where it is a more effective highpass filter.

Now that the SS kernel has been largely dismissed, the task is to choose the better deterministic modifier. 
Table 3 Statistics of the residual gravimetric components of AUSGeoid98 and AUSGeoid09, showing the improvement offered by EGM2008 because the residuals are smaller

\begin{tabular}{lll}
\hline Units $(\mathrm{m})$ & $\begin{array}{l}\text { Residual AUSGeoid98 with respect } \\
\text { to EGM96 to degree } 360\left(2^{\prime} \times 2^{\prime}\right. \\
\text { grid) }\end{array}$ & $\begin{array}{l}\text { Residual AUSGeoid09 with } \\
\text { respect to EGM2008 to degree } \\
2,190\left(1^{\prime} \times 1^{\prime} \text { grid }\right)\end{array}$ \\
\hline No & $1,781,101$ & $7,113,600$ \\
Max & 3.506 & 0.244 \\
Min & -11.422 & -0.619 \\
Mean & -0.049 & -0.005 \\
STD & 0.409 & 0.028
\end{tabular}

The Wong and Gore (1969) (WG) modified kernel is the simplest of all the deterministic modifiers; it only subtracts the low-degree Legendre polynomial terms from the SS kernel (cf. Omang and Forsberg 2002). The Featherstone et al. (1998b) (FEO) modified kernel is more sophisticated because it combines the benefits of several other modifiers, notably by minimising the L 2 norm of the truncation bias and causing it to converge to zero more quickly. The deterministic modifications listed in Featherstone (2003) were also trialed, but the general conclusions reached are the same as presented below.

First, whether a simple WG or a more sophisticated FEO deterministic modification is applied, the results are just as good as (for small cap radii) or better than (for large cap radii) the SS kernel (Fig. 6). Somewhat subjectively, the FEO kernel was chosen over the WG and SS kernels, but it does give slightly smoother and less oscillating results versus cap radii. It is also chosen on theoretical grounds as it combines the benefits of numerous other modifiers (Featherstone et al. 1998b). The one-degree cap radius gives the best improvement over EGM2008, but it is only $\sim \pm 10 \mathrm{~mm}$ in STD (Fig. 6, left panel). This is a strong reflection of the new challenges that EGM2008 has set for regional quasi/geoid computation. Looking at Tables 1 and 3 , the residual quantities being dealt with are considerably smaller than when dealing with EGM96 to degree 360. Quite simply, EGM2008 is a good model of the quasigeoid over Australia (cf. Claessens et al. 2009).

The choice of the degree of modification is also somewhat subjective since the results for different degrees are nearidentical for the one-degree spherical cap radius. A degree40 modification was chosen ultimately for the following reasons. First, the results oscillate more for higher degrees of FEO modification in Fig. 6 because the modified kernel oscillates more, so the kernel value at the centre of each cell is not representative of the mean across the cell in the numerical integration. Second, from the analysis of Koch (2005), the stochastic properties of GRACE-only static gravity fields indicate that up to degree-60 is more reliable. Hence, a com- promise was made between degree- 60 and the very smooth results achieved for the degree-20 kernel (Fig. 6, bottom panels).

A curious feature is seen when comparing the left and right panels of Fig. 6, where the agreement becomes slightly worse than EGM2008 alone for larger cap radii for the GNSSANLN data, whereas it is consistently better than EGM2008 for the GNSS-AHD data, improving with increasing cap radius for the FEO kernels. This is enigmatic, but it is possibly due to the distortions in the AHD masking the selection of the best integration parameters. The results in the left panels of Fig. 6 are considered more reliable, first because of the lower STD, but also intuitively because the larger cap radius lessens the power of the high-pass filtering of terrestrial data errors, thus giving worse results, as was the extreme case for the SS kernel.

\subsection{The residual gravimetric quasigeoid}

Figure 7 shows the residual gravimetric quasigeoid computed from the residual gravity anomalies (Fig. 5) by the 1DFFT technique with a degree-40 FEO modified kernel over a one-degree-radius spherical cap. From Table 3, this residual gravimetric quasigeoid is an order of magnitude less than the residual-to-EGM96 value computed for AUSGeoid98 (Featherstone et al. 2001), reflecting the reduction in the omission error by the degree-2,190 expansion of EGM2008. The larger residual quasigeoid signal in the Great Dividing Range along the south-eastern seaboard and in Tasmania is due to topography. However, there are few GNSS-levelling points in these regions to properly quantify any improvement offered. As such, it is recommended that good quality levelling and GNSS data are acquired in mountainous regions if topographical effects are to be assessed more objectively.

Figures 8 and 9 show the differences between the gravimetric-only component of AUSGeoid09 and GNSS-levelling data: Fig. 8 maps the differences with respect to the published/official AHD heights showing the north-south tilt and regional distortions in the AHD (cf. Featherstone 2004, 2006; Featherstone and Filmer 2008; Filmer and Featherstone 
Fig. 7 Residual quasigeoid undulations (m) with respect to EGM2008, computed by

1D-FFT numerical integration of Stokes's formula with the FEO modified kernel for a one-degree spherical cap radius and degree- 40 modification

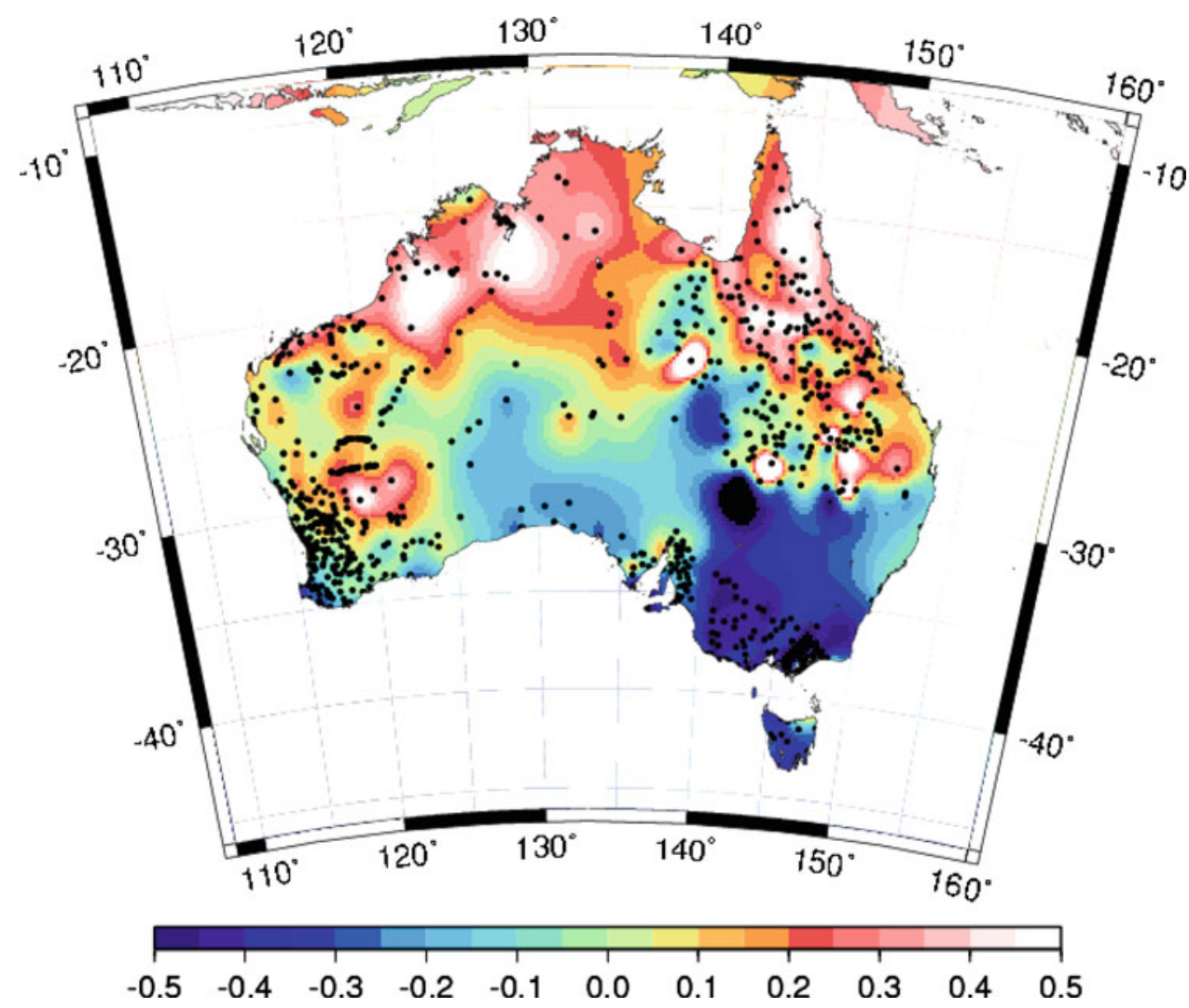

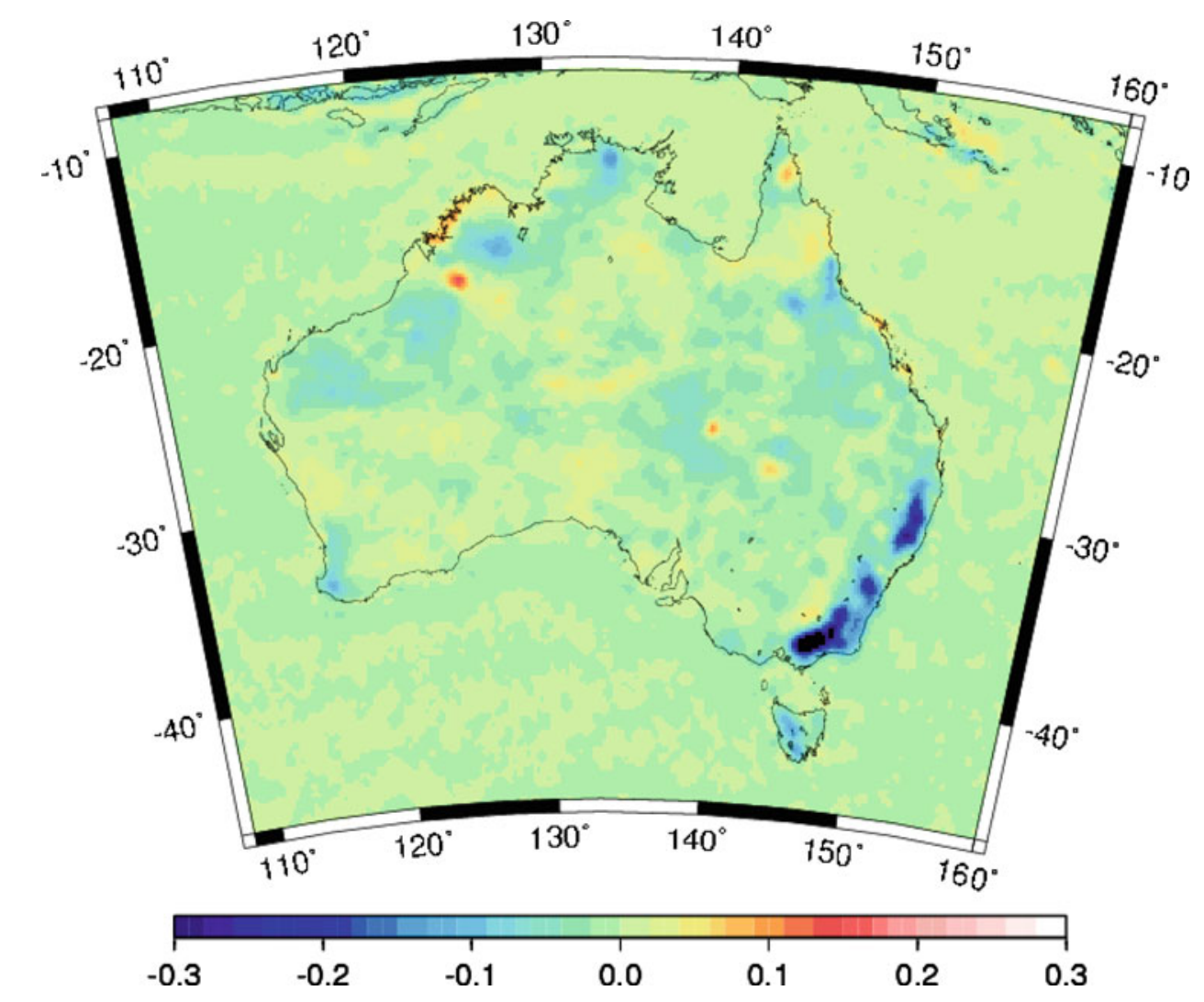

Fig. 8 Differences (m) between the gravimetric component of AUSGeoid09 and published/official GNS-AHD heights. There is a dominant north-south trend and higher order distortions due principally to the poor quality of the AHD. There is extrapolation into New South Wales and northern South Australia because of the lack of GNSS data in these regions for the testing phase of AUSGeoid09

\section{AUSGeoidos}


Fig. 9 Differences (m) between the gravimetric component of AUSGeoid09 and readjusted GNSS-ANLN heights. The north-south trend has lessened (cf. Fig. 9), but regional distortions remain because of the poor quality of the ANLN data. There is extrapolation into New South Wales and northern South Australia because of the lack of GNSS data in these regions for the testing phase of AUSGeoid09

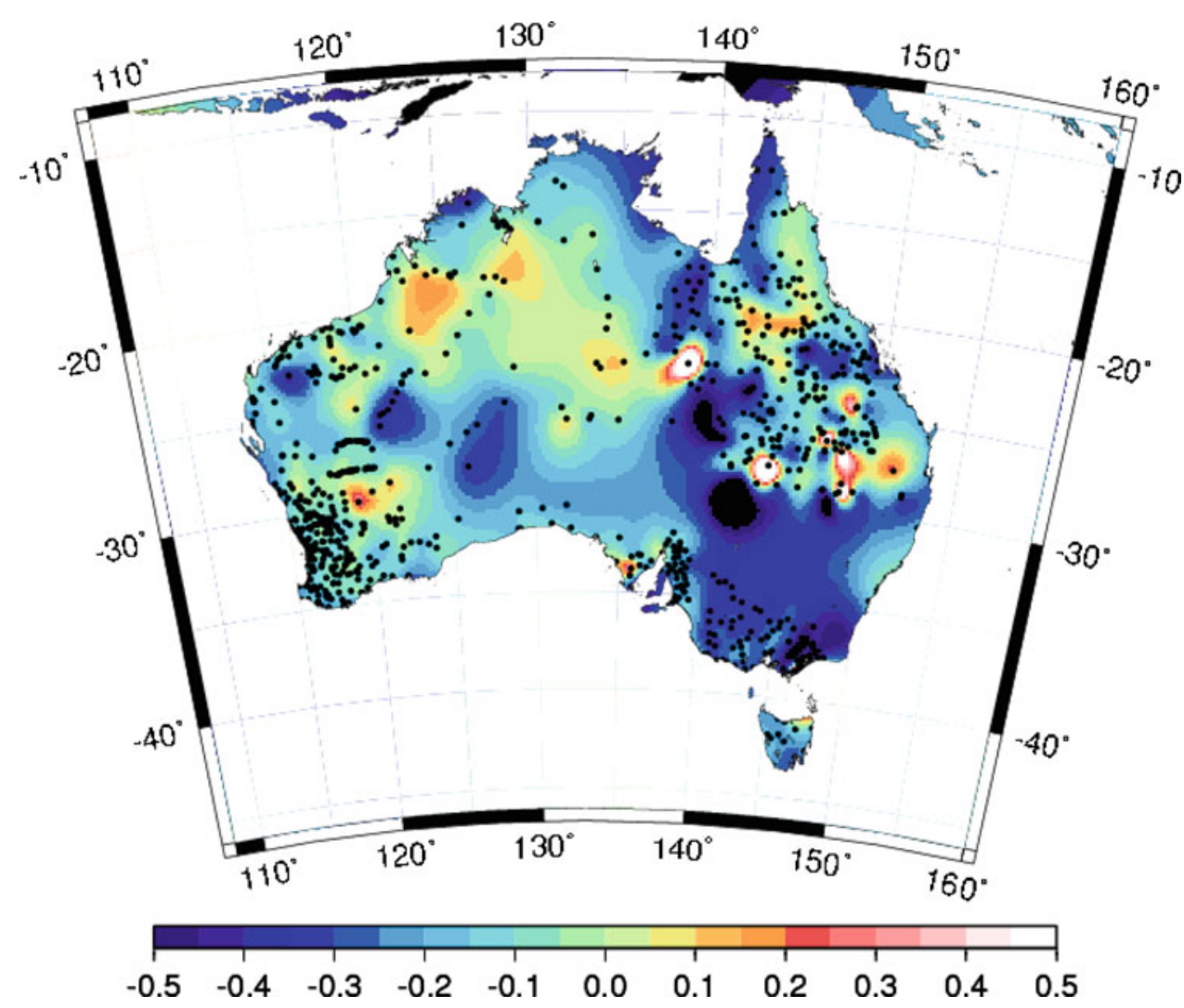

2009); Fig. 9 shows the differences with respect to the readjusted ANLN heights (Sect. 2.7). In addition to Fig. 6, this confirms that assessing the gravimetric component of AUSGeoid09 by the readjusted levelling is a better 'litmus test', but is still limited by the quality of the ANLN.

\section{Fitting the gravimetric quasigeoid to the AHD}

To provide a practically useful product for GNSS users wanting to more directly determine AHD heights (cf. Featherstone 1998, 2008; Featherstone and Stewart 2001), the gravimetric component of AUSGeoid09 (Sect. 3) was warped/distorted to fit the surface of zero elevation of the AHD using least-squares collocation (LSC) in a cross-validation mode (Featherstone and Sproule 2006). LSC is useful for this purpose because it is a data-driven interpolation technique that takes into consideration the spatial distribution and uncertainty of the data. Moreover, it has proven to be useful in many previous similar studies (e.g., Smith and Roman 2001; Featherstone 2000). The benefit of the cross-validation approach is that quasi-independent data are used to determine the empirical covariance function (Featherstone and Sproule 2006).

Although ITRF2005 was used as the ellipsoidal height reference frame for testing the gravimetric component of AUSGeoid09 (Sect. 3.2), GDA94 ellipsoidal heights are used in the geometric component of AUSGeoid09. This is deliberate so as to avoid confusion (ITRF2005 and its various epochs versus GDA94) and an additional stage of computation for the users of AUSGeoid09, where GDA94 heights would need to be transformed to ITRF2005 or vice versa, thus lessening the utility of the 'product'. Since GNSS surveyors in Australia have ready access to GDA94 ellipsoidal heights, the height transformation is more direct and less prone to mistakes associated with using different reference frames.

An extended dataset of 6,794 points was used in LSC cross-validation mode to determine the optimal correlation length for the Gaussian analytical covariance function for the a posteriori fitting. The noise for the empirical covariance function was not determined empirically, but instead used the STD of the post-processed GNSS ellipsoidal heights scaled by an order of magnitude (Sect. 2.7); that is, the noise is prescribed for each GNSS-AHD data point such that the amount of a posteriori fitting is within the expected error of the GNSS ellipsoidal height only, whereas the AHD height is preserved such that the agreement is accommodated within the expected error of the GNSS height. This is pragmatic as it enforces the AHD height to be 'true' while accommodating the uncertainty in the GNSS ellipsoidal height used in the fitting.

The primary dataset for the fitting comprised 2,561 GNSSAHD benchmarks at which the GNSS ellipsoidal heights were observed. The secondary dataset comprised 4,233 levelling junction points at which the ellipsoidal heights 


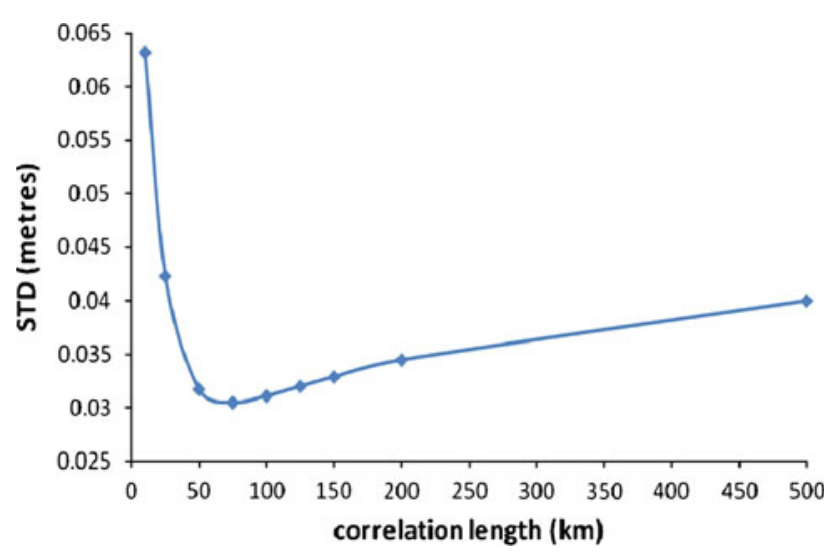

Fig. 10 Misfits (m) for a variety of LSC cross-validation tests for varying correlation lengths of the covariance function using 6,794 discrete data points. The optimal correlation length is $75 \mathrm{~km}$

were derived. For both, the AHD heights were taken as their published/official values. The derived, not observed, AHD heights (i.e., ellipsoidal minus gravimetric quasigeoid heights) at the 2,561 benchmarks were held fixed in a leastsquares readjustment of the ANLN, which effectively warped the AHD heights of the 4,233 junction points onto the gravimetric component of AUSGeoid09. Adding these derived AHD heights of the junction points to the gravimetric quasigeoid values yielded derived ellipsoidal heights. While this is not as good as using observed ellipsoidal heights, it served to provide more and a better spatial coverage of the points used in the fitting. The STD of the derived ellipsoidal heights at the 4,233 junction points derived from the adjustment were then used for the noise in the LSC fitting. These were relatively large compared to the noise values of the primary dataset, reflecting that the secondary dataset of derived ellipsoidal heights were not observed with GNSS. As such, the amount of fitting is lessened at these less reliable points.

As opposed to omitting high quality data points from the dataset to be later used as checkpoints (cf. Featherstone 2000) or using the same data points used to construct the model to verify to the model, LSC cross-validation was used. In turn, one data point was omitted from the dataset, the remaining 6,793 points were used to produce the fitted model, and the omitted point was used as a pseudo-independent checkpoint. This was repeated for each of the 6,794 data points. From each of the nine tests of varying correlation lengths the fitted model with the smallest RMS misfit of $\pm 30 \mathrm{~mm}$ was found for a LSC correlation length of $75 \mathrm{~km}$ (Fig. 10).

\section{Concluding remarks}

We have described the computation of the AUSGeoid09 model of the surface of zero elevation of the Australian
Height Datum (AHD), first through the computation of a regional gravimetric-only quasigeoid model, then through posteriori fitting to GNSS-AHD heights via cross-validated LSC. The overarching strategy was to provide a practically useful 'product' for the more direct determination of AHD heights from GNSS than was achievable previously with its decade-old predecessor AUSGeoid98, but appreciating that this approach does not provide any better determination of the true Australian quasigeoid; it is simply an interim solution. During this process, it was realised that EGM2008 has set some challenges for regional quasi/geoid modelling, but it has also offered some advantages. In the Australian case, EGM2008 has confirmed some known deficiencies in AUSGeoid98, but also uncovered some unknown deficiencies that are corroborated by other studies.

The improvement achieved in terms of STD of fit to GNSS-levelling data of the gravimetric component of AUSGeoid09 over EGM2008 is only $\sim \pm 10 \mathrm{~mm}$, reflecting the good quality of EGM2008 over Australia and the new challenges it has set for regional quasi/geoid computations. While this may indicate that EGM2008 can be used alone over Australia, it does not yield heights from GNSS that are always compatible with [the tilted and distorted] AHD. Instead, the fitted version of AUSGeoid09 is a preferable product for Australian GNSS heighting, where (albeit using different sample sizes) the STD of fit to the AHD is reduced from $\pm 231 \mathrm{~mm}$ for EGM2008 to $\pm 30 \mathrm{~mm}$ for AUSGeoid09. The denser $1^{\prime} \times 1^{\prime}$ grid spacing of AUSGeoid09 also reduces omission and interpolation errors.

The auxiliary conclusions and recommendations from this work are that (1) some more consideration needs to be given to the terminology of 'corrector' surface, with a view to standardisation and realisation that there is strictly no correction taking place; (2) there is a disparity among various height systems and quasi/geoid models that needs to be better acknowledged; (3) quasi/geoid modelling in coastal and mountainous zones needs far more attention; (4) the quality of GNSS-levelling data, especially the levelling data for this study, used to assess gravimetric quasi/geoid models needs far more attention; (5) filtering of long-wavelength errors from terrestrial gravity anomalies before regional quasi/geoid computation is a now a necessity, whether it be via modified kernels or another approach.

Postscript: AUSGeoid09 will be released soon by Geoscience Australia, but the gravimetric-only version, termed AGQG2009 (cf. Smith and Roman 2001), will only be released on a restricted basis so as not fragment Australia's spatial data infrastructure.

Acknowledgments Will Featherstone is the recipient of an Australian Research Council (ARC) Professorial Fellowship (project number DP0663020). Christian Hirt is supported under the ARC's 
Discovery Projects funding scheme (project number DP0663020). The views expressed herein are those of the authors and are not necessarily those of the ARC. Mick Filmer receives financial support from an Australian Postgraduate Award, Curtin University's Institute for Geoscience Research and the Cooperative Research Centre for Spatial Information. This work was also supported by iVEC (http://www.ivec.org/) through the use of advanced computing resources provided by the SGI Altix facility located at Technology Park, Perth, Australia. Some of our figures were produced using the Generic Mapping Tools (GMT; Wessel and Smith 1998). Nicholas Brown, Guorong Hu and Gary Johnston publish with the permission of the Chief Executive Officer of Geoscience Australia. Special thanks go to the Danish National Space Centre, CSIRO Marine Laboratories and the US National Geospatial Intelligence Agency for making their data freely available. Thanks also go to J. Hicks for proofreading and productive discussions and to the three anonymous reviewers for their very perceptive, thorough and rapid reviews. This is The Institute for Geoscience Research (TIGeR) publication number 234 .

Open Access This article is distributed under the terms of the Creative Commons Attribution Noncommercial License which permits any noncommercial use, distribution, and reproduction in any medium, provided the original author(s) and source are credited.

\section{References}

Altamimi Z, Collilieux X, Legrand J, Garayt B, Boucher C (2007) ITRF2005: a new release of the International Terrestrial Reference Frame based on time series of station positions and Earth Orientation Parameters. J Geophys Res 112:B09401. doi:10.1029/ 2007JB004949

Andersen OB, Knudsen P (2000) The role of satellite altimetry in gravity field modelling in coastal areas. Phys Chem Earth Part A 25(1):17-24. doi:10.1016/S1464-1895(00)00004-1

Andersen OB, Knudsen P, Berry PAM (2010) The DNSC08GRA global marine gravity field from double retracked satellite altimetry. J Geod 84(3):191-199. doi:10.1007/s00190-009-0355-9

Barlow BC (1977) Data limitations on model complexity; 2-D gravity modelling with desk-top calculators. Bull Aust Soc Explor Geophys 8(4):139-143. doi:10.1071/EG977139

Bellamy CJ, Lodwick GD (1968) The reduction of barometric networks and field gravity surveys. Surv Rev 19(147):216-227

Claessens SJ (2006) Solutions to the ellipsoidal boundary value problems for gravity field modelling. PhD thesis, Curtin University of Technology, Perth

Claessens SJ (2010) Evaluation of gravity and altimetry data in Australian coastal regions. In: Proceedings of the IAG2009 Symposium Geodesy for Planet Earth, Buenos Aires, August-September 2009

Claessens SJ, Featherstone WE, Barthelmes F (2001) Experiments with point-mass gravity field modelling in the Perth region, Western Australia. Geomatics Res Australas 75:53-86

Claessens SJ, Featherstone WE, Anjasmara IM, Filmer MS (2009) Is Australian data really validating EGM2008, or is EGM2008just in/validating Australian data? Newton's Bull 4:207-251

Dach R, Hugentobler U, Fridez P, Meindl M (eds) (2007) Bernese GPS software version 5.0, Astronomical Institute, University of Bern, pp 612

Darbeheshti N, Featherstone WE (2009) Non-stationary covariance function modelling in 2D least-squares collocation. J Geod 83(6):495-508. doi:10.1007/s00190-008-0267-0

Darbeheshti N, Featherstone WE (2010) Tuning a gravimetric quasigeoid to GPS-levelling by non-stationary least-squares collocation. J Geod. doi:10.1007/s00190-010-0377-3
Deng XL, Coleman R, Featherstone WE, Ridgway KR (2009) Assessment of geoid models offshore Western Australia using in-situ measurements. J Coast Res 25(3):581-588. doi:10.2112/ 07-0972.1

Denker H, Barriot JP, Barzaghi R, Fairhead D, Forsberg R, Ihde J, Kenyeres A, Marti U, Sarrailh M, Tziavos IN (2008) The development of the European Gravimetric Geoid model EGG07. In: Sideris MG (ed) Observing our changing Earth. Springer, Berlin pp 177-185. doi:10.1007/978-3-540-85426-5 21

Dow JM, Neilan RE, Rizos C (2009) The International GNSS Service in a changing landscape of global navigation satellite systems. J Geod 83(7):191-198. doi:10.1007/s00190-008-0300-3

Featherstone WE (1997) The importance of including the geoid in terrestrial survey data reduction to the Geocentric Datum of Australia. Aust Surv 42(1):45-50

Featherstone WE (1998) Do we need a gravimetric geoid or a model of the base of the Australian Height Datum to transform GPS heights? Aust Surv 43(4):273-280

Featherstone WE (2000) Refinement of gravimetric geoid using GPS and levelling data. J Surv Eng 126(2):27-56. doi:10.1061/ (ASCE)0733-9453(2000)126:2(27)

Featherstone WE (2001) Absolute and relative testing of gravimetric geoid models using Global Positioning System and orthometric height data. Comput Geosci 27(7):807-814. doi:10.1016/ S0098-3004(00)00169-2

Featherstone WE (2002) Prospects for the Australian Height Datum and geoid model. In: Adam J, Schwarz K-P (eds) Vistas for geodesy in the new millennium. Springer, Berlin pp 96-101

Featherstone WE (2003) Software for computing five existing types of deterministically modified integration kernel for gravimetric geoid determination. Comput Geosci 29(2):183-193. doi:10. 1016/S0098-3004(02)00074-2

Featherstone WE (2004) Evidence of a north-south trend between AUSGeoid98 and the AHD in southwest Australia. Surv Rev 37(291):334-343

Featherstone WE (2006) Yet more evidence for a north-south slope in the AHD. J Spat Sci 51(2):1-6 [Corrigendum in J Spat Sci 52(1):65-68]

Featherstone WE (2007) Augmentation of AUSGeoid98 with GRACE satellite gravity data. J Spat Sci 52(2):75-86

Featherstone WE (2008) GNSS-based heighting in Australia: current, emerging and future issues. J Spat Sci 53(2):115-133

Featherstone WE (2009) Only use ship-track gravity data with caution: a case-study around Australia. Aust J Earth Sci 56(2):191-195. doi:10.1080/08120090802547025

Featherstone WE, Olliver JG (1997) A method to validate gravimetric geoid computation software based on Stokes's integral. J Geod 71(9):571-576. doi:10.1007/s001900050125

Featherstone WE, Sideris MG (1998) Modified kernels in spectral geoid determination: first results from Western Australia. In: Forsberg R, Feissl M, Dietrich R (eds) Geodesy on the move: gravity, geoids, geodynamics, and Antarctica. Springer, Berlin pp 188193

Featherstone WE, Dent V (2002) Transfer of vertical geodetic control using only one GPS receiver: a case study. Aust Surv 47(1):3137

Featherstone WE, Dentith MC, Kirby JF (1998a) Strategies for the accurate determination of orthometric heights from GPS. Surv Rev 34(267):278-296

Featherstone WE, Evans JD, Olliver JG (1998b) A Meissl-modified Vaníček and Kleusberg kernel to reduce the truncation error in gravimetric geoid computations. J Geod 72(3):154-160. doi:10. 1007/s001900050157

Featherstone WE, Filmer MS (2008) A new GPS-based evaluation of distortions in the Australian Height Datum in Western Australia. J R Soc West Aust 91(2):199-206 
Featherstone WE, Kirby JF (2000) The reduction of aliasing in gravity anomalies and geoid heights using digital terrain data. Geophys $\mathrm{J}$ Int 141(1):204-212. doi:10.1046/j.1365-246X.2000.00082.x

Featherstone WE, Kirby JF, Kearsley AHW, Gilliland JR, Johnston GM, Steed J, Forsberg R, Sideris MG (2001) The AUSGeoid98 geoid model of Australia: data treatment, computations and comparisons with GPS-levelling data. J Geod 75(5-6):313-330. doi:10.1007/s001900100177

Featherstone WE, Kuhn M (2006) Height systems and vertical datums: a review in the Australian context. J Spat Sci 51(1):21-42

Featherstone WE, Rüeger JM (2000) The importance of using deviations of the vertical in the reduction of terrestrial survey data to a geocentric datum. Trans-Tasman Surv 1(3):46-61 [Erratum in Aust Surv 47(1):7]

Featherstone WE, Sproule DM (2006) Fitting AUSGeoid98 to the Australian height datum using GPS data and least squares collocation: application of a cross-validation technique. Surv Rev 38(301):573-582

Featherstone WE, Stewart MP (2001) Combined analysis of realtime kinematic GPS equipment and its users for height determination. J Surv Eng 127(2):31-51. doi:10.1061/ (ASCE)0733-9453(2001)127:2(31)

Filmer MS, Featherstone WE (2009) Detecting spirit-levelling errors in the AHD: recent findings and some issues for any new Australian height datum. Aust J Earth Sci 56(4):559-569. doi:10.1080/ 08120090902806305

Filmer MS, Featherstone WE, Kuhn M (2010) The effect of EGM2008based normal, normal-orthometric and Helmert orthometric height systems on the Australian levelling network. J Geod 84(8):501513. doi:10.1007/s00190-010-0388-0

Forsberg R, Tscherning CC (1981) The use of height data in gravity field approximation by collocation. J Geophys Res 86(B9):78437854

Forsberg R, Featherstone WE (1998) Geoids and cap sizes. In: Forsberg R, Feissl M, Dietrich R (eds) Geodesy on the move: gravity, geoids, geodynamics, and Antarctica. Springer, Berlin pp 194-200

Fraser AR, Moss FJ, Turpie A (1976) Reconnaissance gravity survey of Australia. Geophysics 41:1337-1345. doi:10.1190/1. 1440683

Gilliland JR (1994) Cap sizes in geoid calculations. Aust J Geod Photogramm Surv 60:95-108

Goos JM, Featherstone WE, Kirby JF, Holmes SA (2003) Experiments with two different approaches to gridding terrestrial gravity anomalies and their effect on regional geoid computation. Surv Rev 37(288):92-112

Haagmans R, de Min E, van Gelderen M (1993) Fast evaluation of convolution integrals on the sphere using 1D FFT, and a comparison with existing methods for Stokes' integral. Manuscripta Geod 18(3):227-241

Hackney RI, Featherstone WE (2003) Geodetic versus geophysical perspectives of the 'gravity anomaly'. Geophys J Int 154(1):35-43. doi:10.1046/j.1365-246X.2003.01941.x [Errata in 154(2): 596, doi:10.1046/j.1365-246X.2003.02058.x and 167(2): 585, doi:10. 1111/j.1365-246X.2006.03035.x]

Heck B (1990) An evaluation of some systematic error sources affecting terrestrial gravity anomalies. Bull Geod 64(1):88-108. doi:10. 1007/BF02530617

Heiskanen WH, Moritz H (1967) Physical geodesy. Freeman, San Francisco

Hipkin RG (2000) Modelling the geoid and sea-surface topography in coastal areas. Phys Chem Earth Part A 25(1):9-16. doi:10.1016/ S1464-1895(00)00003-X

Hipkin RG (2004) Ellipsoidal geoid computation. J Geod 78(3):167179. doi:10.1007/s00190-004-0389-y
Hirt C, Filmer MS, Featherstone WE (2010) Comparison and validation of recent freely-available ASTER-GDEM ver1, SRTM ver4.1 and GEODATA DEM-9S ver3 digital elevation models over Australia. Aust J Earth Sci 57(3):337-347. doi:10.1080/ 08120091003677553

Huang J, Véronneau M, Pagiatakis SD (2003) On the ellipsoidal correction to the spherical Stokes solution of the gravimetric geoid. J Geod 77(3-4):171-181. doi:10.1007/s00190-003-0317-6

Hutchinson MF, Stein JA, Stein JL (2008) GEODATA 9 second digital elevation model version 3 and flow direction grid: user guide. Fenner School of Environment and Society, Australian National University and Geoscience Australia

ICSM (2007) Standards and practices for control surveys. Special Publication 1 (SP1), version 1.7, Intergovernmental Committee on Surveying and Mapping, Canberra

Janak J, Vaníček P (2005) Mean free-air gravity anomalies in the mountains. Stud Geophys Geod 49(1):31-42. doi:10.1007/ s11200-005-1624-6

Jekeli C, Serpas JG (2003) Review and numerical assessment of the direct topographical reduction in geoid determination. J Geod 77(3-4):226-239. doi:10.1007/s00190-003-0320-y

Kearsley AHW (1988a) Tests on the recovery of precise geoid height differences from gravimetry. J Geophys Res 93(B6):6559-6570. doi:10.1029/JB093iB06p06559

Kearsley AHW (1988b) The determination of the geoid-ellipsoid separation for GPS levelling. Aust Surv 34(1):11-18

Kirby JF (2003) On the combination of gravity anomalies and gravity disturbances for geoid determination in Western Australia. J Geod 77(7-8):433-439. doi:10.1007/s00190-003-0334-5

Kirby JF, Featherstone WE (1997) A study of zero- and first-degree terms in geopotential models over Australia. Geomatics Res Aust 66:93-108

Kirby JF, Featherstone WE (2001) Anomalously large gradients in the "GEODATA 9 Second" digital elevation model of Australia, and their effects on gravimetric terrain corrections. Cartography 30:110

Kirby JF, Featherstone WE (2002) High-resolution grids of gravimetric terrain correction and complete Bouguer corrections over Australia. Explor Geophys 33(4):161-165. doi:10.1071/EG00109

Koch KR (2005) Determining the maximum degree of harmonic coefficients in geopotential models by Monte Carlo methods. Stud Geophys Geod 49(3):259-275. doi:10.1007/s11200-005-0009-1

Kuhn M, Featherstone WE, Kirby JF (2009) Complete spherical Bouguer gravity anomalies over Australia. Aust J Earth Sci 56(2):209_ 219. doi:10.1080/08120090802547041

Lambeck K (1987) The Perth Basin: a possible framework for its formation and evolution. Explor Geophys 18(2):124-128. doi:10. 1071/EG987124

Lemoine FG, Kenyon SC, Factor JK, Trimmer RG, Pavlis NK, Chinn DS, Cox CM, Klosko SM, Luthcke SB, Torrence MH, Wang YM, Williamson RG, Pavlis EC, Rapp RH, Olson TR (1998) The development of the joint NASA GSFC and the National Imagery and Mapping Agency (NIMA) geopotential model EGM96, NASA/TP-1998-206861, National Aeronautics and Space Administration, USA

McCarthy DD, Petit G (eds) (2004) IERS Conventions 2003, Technical Note 32, International Earth Rotation and Reference Systems Service, Verlag des Bundesamts für Kartographie und Geodäsie, Frankfurt am Main, Germany

McLaren S, Wallace MW (2010) Plio-Pleistocene climate change and the onset of aridity in southeastern Australia. Global Planet Change 71(1-2):55-72. doi:10.1016/j.gloplacha.2009.12.007

Miranda JA, Wallace MW, McLaren S (2008) The Norwest Bend Formation: implications for the evolution of Neogene drainage in southeastern Australia. Sediment Geol 205(1-2):53-66. doi:10. 1016/j.sedgeo.2008.01.007 
Molodensky MS, Eremeev VF, Yurkina MI (1962) Methods for study of the external gravity field and figure of the Earth. Israeli Program for Scientific Translations, Jerusalem

Morelli C, Gantar C, Honkaslo T, McConnel RK, Tanner TG, Szabo B, Uotila U, Whalen CT (1971) The International Gravity Standardisation Network (IGSN71), Special Publication 4 of Bulletin Géodésique

Morgan PJ (1992) An analysis of the Australian Height Datum: 1971. Aust Surv 37(1):46-63

Moritz H (1968) On the use of the terrain correction in solving Molodensky's problem, Report 108, Department of Geodetic Science and Surveying. Ohio State University, Columbus

Moritz H. (1980) Geodetic Reference System 1980. Bull Géod 54(3):395-405. doi:10.1007/BF02521480

Murray AS (1997) The Australian national gravity database. AGSO J Aust Geol Geophys 17:145-155

Omang OCD, Forsberg R (2002) The northern European geoid: a case study on long-wavelength geoid errors. J Geod 76(6-7):369-380. doi:10.1007/s00190-002-0261-x

Pavlis NK (1998) Observed inconsistencies between satellite-only and surface gravity-only geopotential models. In: Forsberg R, Feissl M, Dietrich R (eds) Geodesy on the move: Gravity, Geoids, Geodynamics, and Antarctica. Springer, Berlin Heidelberg New York pp 144-149

Pavlis NK (2000) On the modelling of long wavelength systematic errors in surface gravimetric data. In: Schwarz K-P (ed) Geodesy beyond 2000. Springer, Berlin pp 131-136

Pavlis NK, Factor JK, Holmes SA (2006) Terrain-related gravimetric quantities computed for the next EGM. In: Forsberg R, Kiliçoğlu A (eds) 1st international symposium of the international gravity field service, gravity field of the Earth, General Command of Mapping, Special Issue 18, Istanbul, pp 318-323

Pavlis NK, Holmes SA, Kenyon SC, Factor JK (2008) An Earth Gravitational Model to degree 2160: EGM2008. In: Paper presented at the general assembly of the European Geosciences Union, Vienna

Rapp RH (1961) The orthometric height, MS Dissertation. The Ohio State University, Columbus

Ridgway KR, Dunn JR, Wilkin JL (2002) Ocean interpolation by fourdimensional least squares - application to the waters around Australia. J Atmos Ocean Technol 19(9):1357-1375. doi:10.1175/ 1520-0426(2002)019<1357:OIBFDW>2.0.CO;2

Roelse A, Granger HW, Graham JW (1971) The adjustment of the Australian levelling survey 1970-1971, Report 12, Division of National Mapping, Canberra

Rothacher M (2002) Estimation of station heights with GPS. In: Drewes H, Dodson A, Fortes LPS, Sánchez L, Sandoval P (eds) Vertical reference systems. Springer, Berlin pp 81-90

Sandwell DT, Smith WHF (2009) Global marine gravity from retracked Geosat and ERS-1 altimetry: ridge segmentation versus spreading rate. J Geophys Res Solid Earth 114:B01411. doi:10.1029/ 2008JB006008

Schmid R, Steigenberger P, Gendt G, Ge M, Rothacher M (2007) Generation of a consistent absolute phase center correction model for GPS receiver and satellite antennas. J Geod 81(12):781-798. doi:10.1007/s00190-007-0148-y

Sideris MG (1990) Rigorous gravimetric terrain modeling using Molodensky's operator. Manuscripta Geod 15:97-106

Sjöberg LE (2005) A discussion on the approximations made in the practical implementation of the remove-compute-restore technique in regional geoid modeling. J Geod 78(11-12):645-653. doi:10.1007/s00190-004-0430-1
Smith WHF, Wessel P (1990) Gridding with continuous curvature splines in tension. Geophysics 55(3):293-305. doi:10.1190/1. 1442837

Smith DA, Roman DR (2001) GEOID99 and G99SSS: 1-arc-minute geoid models for the United States. J Geod 75(9-10):469-490. doi: $10.1007 / \mathrm{s} 001900100200$

Soltanpour A, Nahavandchi H, Featherstone WE (2006) The use of second-generation wavelets to combine a gravimetric geoid model with GPS-levelling data. J Geod 80(2):82-93. doi:10.1007/ s00190-006-0033-0

Sproule DM, Featherstone WE, Kirby JF (2006) Localised gross-error detection in the Australian land gravity database. Explor Geophys 37(2):175-179. doi:10.1071/EG06175

Tapley BD, Bettadpur S, Watkins M, Reigber C (2004) The Gravity Recovery and Climate Experiment: mission overview and early results. Geophys Res Lett 31:L09607. doi:10.1029/ 2004GL019920

Tracey R, Bacchin M, Wynne P (2007) AAGD07: a new absolute gravity datum for Australian gravity and new standards for the Australian National Gravity Database, ASEG Extended Abstracts. doi:10. 1071/ASEG2007ab149

Tregoning P, Lambeck K, Ramillien G (2008) GRACE estimates of sea surface height anomalies in the Gulf of Carpentaria, Australia. Earth Planet Space Lett 271(1-4):241-244. doi:10.1016/j.epsl. 2008.04.018

Val'ko M, Mojzeš M, Janák J, Papčo J (2008) Comparision of two different solution to Molodensky's G1 term. Stud Geophys Geod 52(1):71-86. doi:10.1007/s11200-008-0006-2

Vaníček P (1991) Vertical datum and NAVD88. Surv Land Inform Syst 51(2):83-86

Vaníček P, Tenzer R, Sjöberg LE, Martinec Z, Featherstone WE (2004) New views of the spherical Bouguer gravity anomaly. Geophys J Int 159(2):460-472. doi:10.1111/j.1365-246X.2004. 02435. X

Vaníček P, Kleusberg A (1987) The Canadian geoid-Stokesian approach. Manuscripta Geod 12(1):86-98

Vaníček P, Sjöberg LE (1991) Reformulation of Stokes's theory for higher than second-degree reference field and modification of integration kernels. J Geophys Res Solid Earth 96(B4):6529-6539

Vaníček P, Featherstone WE (1998) Performance of three types of Stokes's kernel in the combined solution for the geoid. J Geod 72(12):684-697. doi:10.1007/s001900050209

Wellman P, Barlow BC, Murray AS (1985) Gravity base station network values, Report 261, Australian Geological Survey Organisation, Canberra

Wessel P, Smith WHF (1996) A global self-consistent, hierarchical, and high-resolution shoreline database. J Geophys Res 101(B4):87418743. doi:10.1029/96JB00104

Wessel P, Smith WHF (1998) New, improved version of Generic Mapping Tools released. EOS Trans Am Geophys Union 79(47):579

Wong L, Gore R (1969) Accuracy of geoid heights from modified Stokes' kernels. Geophys J R Astron Soc 18(1):81-91

Zhang KF, Featherstone WE (2004) Investigation of the roughness of the Australian gravity field using statistical, graphical, fractal and Fourier power spectrum techniques. Surv Rev 37(293):520-530

Zumberge JF, Heflin MB, Jefferson DC, Watkins MM, Webb FH (1997) Precise point positioning for the efficient and robust analysis of GPS data from large networks. J Geophys Res 102(B3):5005-5017. doi:10.1029/96JB03860 